\title{
THE AUSTRALIAN NATIONAL UNIVERSITY
}

The School of General Studies

To the Registrar

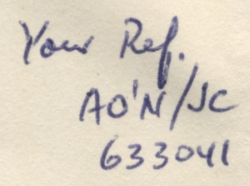

\section{Availability of Thesis}

I understand that the University's regulations provide, inter alia, that theses accepted for degrees of The Australian National University may, for a period of five years after being deposited in the Library, be consulted by persons other than staff and students of the University only with the written consent of the author.

$\varnothing$ I am prepared to waive this rule and to allow my thesis to be consulted by other persons at the discretion of the Librarian.

I also understand that any person (whether a member of the University or not) consulting my thesis will be required to undertake that he will not publish quotations from or substantive information not otherwise available from the thesis without the consent of -

\section{The Austrakoin Atomic Energy Commession}

(Insert here the names of the author and/or, in appropriate circumstances, of the University Department or Committee with responsibilities in relation to confidential sources which have been used in the preparation of the thesis).
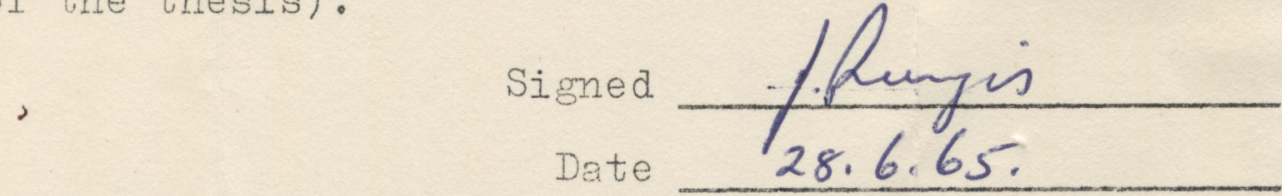

Title of Thesis Diffusion of Calcium in Magnesium Oxide

Date of deposit in Library

$\varnothing$ Cross out whichever is inappropriate. 


\section{DIFFUSION OF CALCIUMI IN MAGNESIUM OXIDE}

Thesis submitted for the degree of

Master of Science

by

Juris Rungis, B.Sc. 
Contents.

page Acknowledgments . . . . . . . . . iv Summery . ..... . . . . . . . . . .

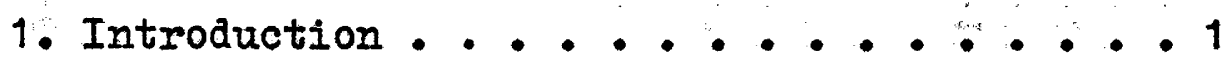
References ............ 6

2. Materials

Details of Single Crystals . . . . . . 7

Details of Polycrystals . . . . . . 10 Referencer . . . . . . . . 13

3. General Method

Radioactive Tracer Technique . . . . 14 Solutions of the Diffusion Equation. . 16 Appendix 3.1 . . . . . . . . 24 References . . . . . . . . 27

4. Experimental Detail

Radioactive Tracer . . . . . . 28

Preparation of Diffusion Couples ... 30 Heat Treatment . . . . . . 30 Temperature Measurement . . . . . 31 Furnace Gradients. . . . . . . 32 Annealing Time . . . . . . . 33 Thermal Expangion. . . . . . . 33 Determination of the Penetration Profiles34 
Resolution . . . . . . . . . 37

Iiniarity . . . . . . . . . 43

Shrinkage, Alignment, Smearing . . . 44 Analysis of Penetration Profiles . . . 46 Summary of Errors . . . . . . 50 References . . . . . . . . 53

5. Principal Results

Ca in Single Crystel MgO . . . . . 54

$\mathrm{Ni}$ in Single Crystal MgO . . . . . 59

$\mathrm{Ca}$ in Polycrystalline MgO. . . . . 59

6. Discussion

Agreement with Published Data . . . 66 Mechanism of Diffusion . . . . . 67 Homogeneity of Crystals. . . . . 69 Frequency Factor . . . . . . 70 $\mathrm{Ni}$ in Single Crygtal MgO. . . . . . 70 Ca in Polycrystalline $\mathrm{MgO}$. . . . 71 References . . . . . . . . . 72

7. Conclusions . . . . . . . 73 


\section{Acknowledgments}

I wish to acknowledge the assistance of the Australian Atomic Energy Commiasion, whose financial support made this work possible. I also wish to thank my supervisor, Dr. A. J. Mortlock for helpful discussions throughout the course of this work. 


\section{$\underline{\text { Summary }}$}

The rate of diffusion of calcium through single crystal magnesium oxide was studied in the temperature range $1000^{\circ} \mathrm{C}$ to $1700^{\circ} \mathrm{C}$. Radioactive ${ }^{45} \mathrm{Ca}$ was used as a tracer and its motion was followed by autoradiography. The temperature dependence of the diffusion coefficients found can be expressed by the relationship:

$$
\text { where } \begin{aligned}
D & =D_{0} \exp (-Q / \mathrm{kT}) \\
D_{0} & =2.7 \times 10^{-5} \mathrm{~cm}^{2} / \mathrm{sec} \\
Q & =2.1 \mathrm{eV}
\end{aligned}
$$

These results agree with previously published work on the diffusion of the transition metal ions, $\mathrm{Fe}, \mathrm{Ni}$ and $\mathrm{Co}$ in magnesium oxide. Several possible diffusion mechanisms which might operate in these cases are discusged.

Some similar measurements of the diffusion of nickel into single crystal magnesium oxide and calcium into polycrystalline magnesium oxide are also described. The results for the polycrystalline aamples show very large peretrations along grain boundaries. 


\section{INTRODUCTION}

At present the Australian Atomic Energy Commission is proposing to build a high-temperature, gas-cooled reactor moderated by beryllium oxide. This material has the attractive nuclear properties ${ }^{1}$ of low absorption cross-section for neutrons and high moderating ratio, as well as being a good ceramic and therefore able to retain its strength at the elevated $\left(800-1000^{\circ} \mathrm{C}\right)$ temperatures to be employed.

The proposed fuel elements ${ }^{2}$ for the reactor will be spheres of beryllium oxide, about an inch in diameter, through which the plutonium and thorium fuel particles have been evenly dispersed. Two of the major practical difficulties associated with this method of reactor construction are the decreasing strength of the beryllia due to boild-up of radlation damage and the contamination of the coolant gas by the loss of fission products. Both of these problems are closely related to the basic atomic diffusion parameters for single and polycrystalline beryllium oxide.

Self diffugion of bergllium oxide will tend to counteract the damage caused by the neutron flux, for as the lattice is distorted, it will tend to heal itself by the random motion of the ions (diffusion). However, to date measurements have only been made of the self-diffusion of beryllium oxtde ${ }^{3,4}$. A step further at this stage would be to investigate methods of increasing the self-diffusion rate, so as to decrease the rate of build-up of the radiation damage. 
An understanding of the loss of fission products requires a knowledge of their diffusion rates as impurities in beryllium oxide. Such information is not available because direct measurements have not yet been made, and because no suitable correlation has yet been established to enable even a rough prediction to be made of their relative rates of diffusion. This situation operates generally for solids of this type, and is to be contrasted with the case of metals where it is now possible to make semi-quantitative predictions of this character in certain systems. For example, a range of impurities has been diffused into the noble metals $\mathrm{Ag}, \mathrm{Au}$ and $\mathrm{Cu}$ and It is found ${ }^{5}$ generally that the relative diffusion rates are controlled by the excess valence of the impurity atoms relative to that of the solvent.

Most of the work to date on cation diffusion in simple oxdies has been restricted to self-diffusion ${ }^{6,7,8}$. The study of the oxides is complicated by the fact that the atmosphere under which the diffusion takes place has to be specified. The concentration of oxygen vacancies will vary with the partial pressure of oxygen in the atmosphere during annealing and this will influence the diffusi on rates. Therefore, if two experiments are to be compared sensibly, they must have been carried out in the same atmosphere. In a more general way, before comparisons between the impurity diffusion rates in different solvents can be made, the relative diffugion rates 
of a range of impurities in the individual solvents should be measured, so as to reveal first of all the parameters goveming the variation in the simpler situation. When these parameters have been established in a number of solvents, comparisons between solvents and therefore extrapolation to others becomes possible.

As far as is known, only one such investigation has been carried out in the case of simple oxides. Wuensch and Vasilos 9 measured the diffusion of the transition metal ions, iron, cobalt, and nickel in single crystal magnesium oxide. They found that the logarithm of the activation energy for impurity cation diffusion in magnesia is proportional to the ratio of the radius of the cation to its ionic electronic polarizability. (fig.1.1) In terms of an equation fitted by least squares, this result may be written:

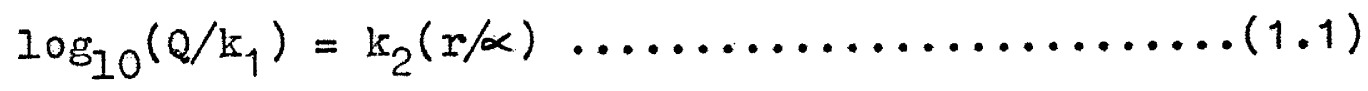

where $\quad Q=$ activation energy in $\mathrm{eV}$ $r=$ ionic radius in $\mathrm{cm}$ $\alpha=$ ionic electronic polarizability in $\mathrm{cm}^{3}$

$$
\begin{aligned}
& \mathrm{k}_{1}=1.40 \mathrm{eV} \\
& \mathrm{k}_{2}=0.0662 \times 10^{-16} \mathrm{~cm}^{2}
\end{aligned}
$$

The aim of the present work, the diffusion of calcium in magnesium oxide, is to extend the data on impurity diffusion in oxides generally, and in particular to test whether the correlation suggested in the magnesium oxide system holds for other than transition metal ions. It is possible that this 


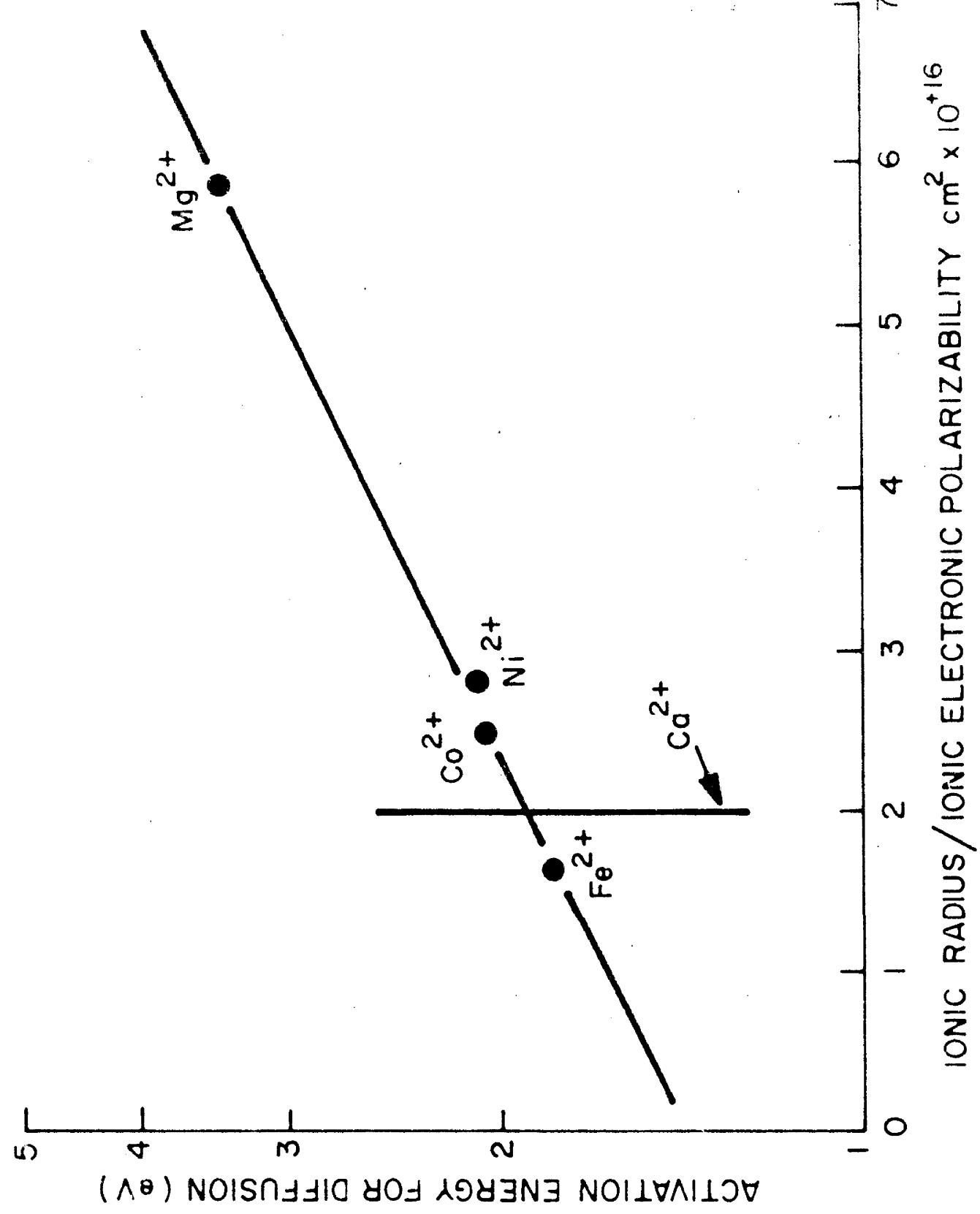


type of relationship may be found, in due course, to be appIicable to other systems such as beryllium oxide. From what has been said above, this could lead to a better understanding of auch diffusion-controlled properties as the loss of fission products from beryllia-moderated fuel elements. 
REFERENCES Chap. 1

(1) I.H.Van VIack, "Physical Ceramics for Engineerg" p 220 Addison- Wesley (1964).

(2) Australian Atomic Energy Commission, Twelfth Annual Report (1963-64):

(3) S.B.Austerman, International Conference on Beryllium Oxide, Newport Australia, (1963).

(4) H.J.de Bruin a.M. Watson, International Conference on Beryllium Oxide, Newport, (1963).

(5) C.Ieymonie, "Radioactive Tracers in Physical Hetallurgy" p 69, Chapman \& Hall (1963).

(6) Ibid p 172

(7) B.I.Boltaks, "Diffusion in Semi-conductors" p 260, Infosearch, Iondon, (1963).

(8) C.E.Birchenall, Met. Revs., 3, 235 (1958).

(9) B.J.Wuensch \& T.Vasilos, J. of Chem. Phys., 36, 2917 (1962) 
2. MATERIALS

Details of Single Crystals.

Diffusion experiments were carried out in virtually all cases using single crystals of magnesium oxide, some of the properties of which are listed in table 2.1. As diffusion rates in the case of ionic solids have been found to be strongly dependent on defect and impurity content ${ }^{1}$, it was important to ensure that in the present study crystals of the highest purity available were used. Analysis of the present crystals and those used by previous authors are given in table 2.2. The crygtals supplied by the Norton Co., Worcester, Mass. and by Semi-Elements Inc., Saxonburg, Pa. both have a purity of only $99.7 \%$ according to the manufacturers. As can be seen from the table, various authors have found these crystals purer than this. The explanation given ${ }^{2}$ is that the manufacturer's data represents a batch purity and that large variations can be found between individual crystals. Wuensch and Vasilos ${ }^{3}$ used the colour of the Norton crystal as an indication of their purity. They assumed that the colourless crystals were purer than the ones with an amber colour, and this was confirmed by their analysis. On the other hand, Bowen ${ }^{4}$ states that he found no relation between the colour and the impurity content. The impurity content of the crystals manufactured by W. \& C. Spicer Ltd., GIos., England is 


\section{Table 2.1}

\section{Properties of MgO Single Crystalg}

Property

Molecular weight

Density

Structure

Refractive index

Colour

Melting point

Coefficient of expansion

Cleavage
Value

40.32

$3.65 \mathrm{gm} / \mathrm{cc}$

f.c.c.

1.736

colourless

$2800^{\circ} \mathrm{C}$

$16 \times 10^{-6}{ }^{\circ} C^{-1}$

[100] planes 


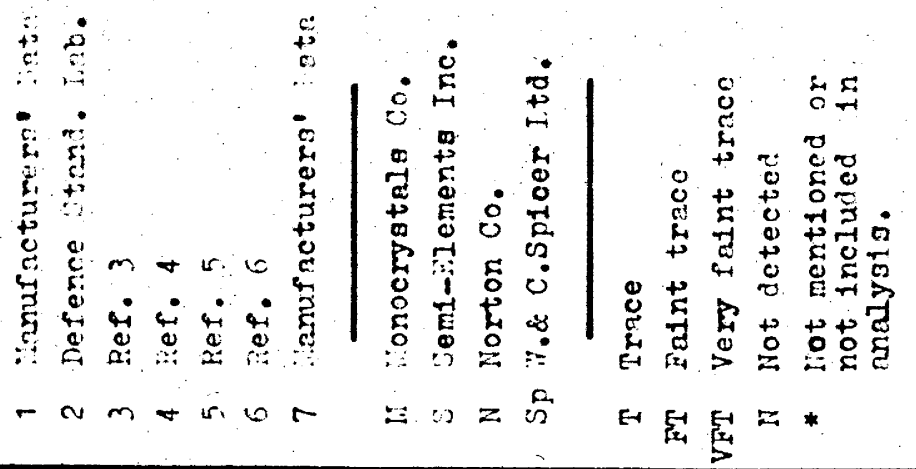

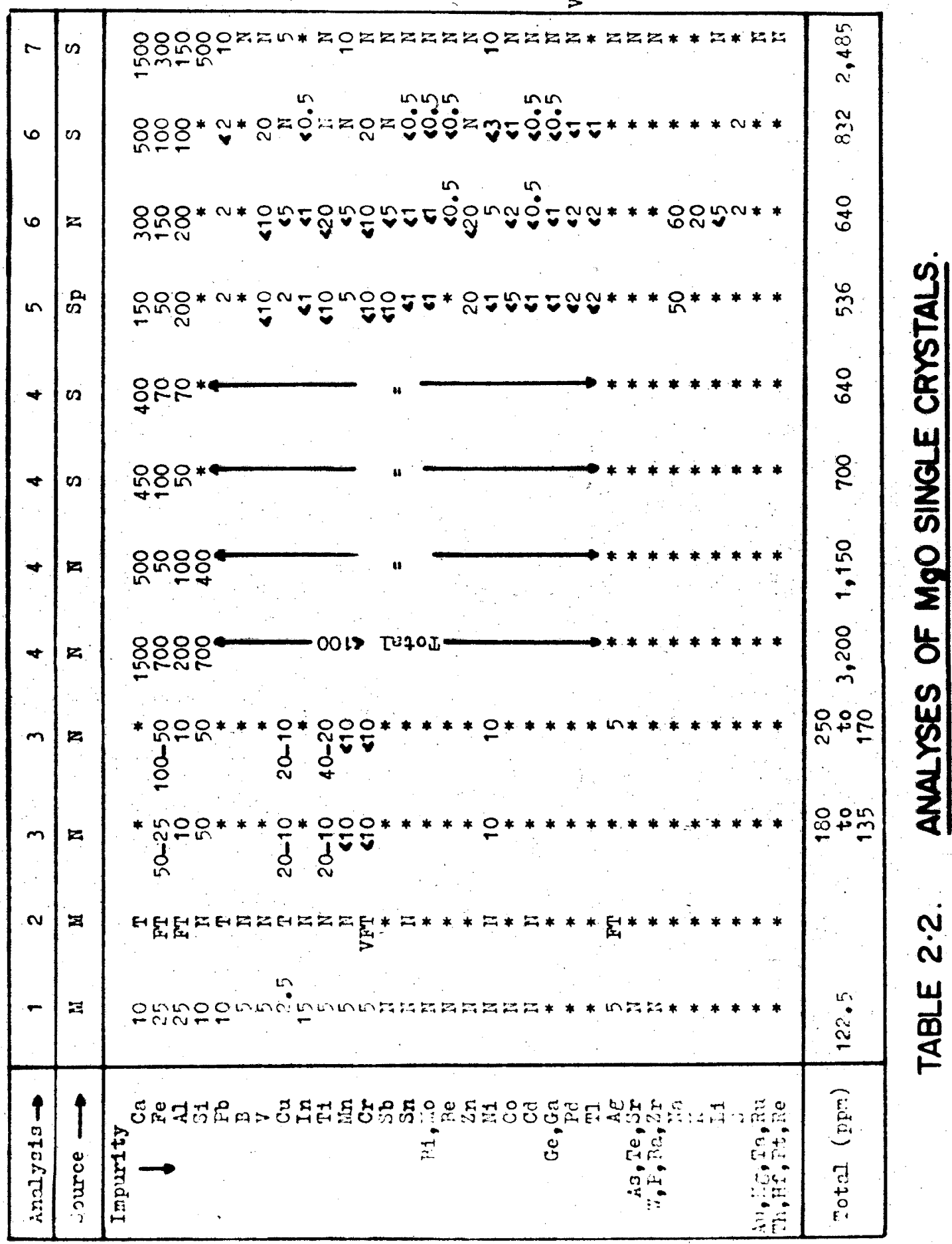


nearly identical ${ }^{5}$ with those from the American sources.

The present source of supply, the Monocrystals Co., Cleveland, Ohio, seems to be superior to any previously cited in the Iiterature. The crystals show no colouration whatsoever, so the problem of grading by colour does not arise. They come in the convenient form of right cylinders $\frac{1}{4} "$ diameter by $\frac{1}{4} "$ long. The analysis of these crystals by the Defence Standards Laboratory, Melbourne, although only a qualitative one, seems to confirm the manufacturer's claim of a $99.99 \%$ purity. Details of Polycrystals

Some experiments were also carried out on polycrystalline magnesium oxide. This material was supplied by Semi-Elements Inc. and had a stated purity of $99.97 \%$. The qualitative analyais supplied by the Defence Standards Iaboratory, given in table 2.3, showg that these polycrystals are slightly less pure than the single crystals supplied by the Monocrystals Co., but there is no reason to doubt the manufacturer's claim of a 99.97\% purity. Two types of polycrystalline samples were purchased. One had an average grain diameter of $0.1 \mathrm{~mm}$ and was found, by direct mass and external dimention measurements, to have a dengity of $2.61 \mathrm{gm} / \mathrm{cc}$ or $73 \%$ of the single crystal density. The other had a grain diameter of $1.0 \mathrm{~mm}$ and a density of $3.15 \mathrm{gm} / \mathrm{cc}$ or $86 \%$ of the single crystal density. These low densities indicate the presence of intermal, macroscopic voids. This was confirmed by the many bubbles appearing on the surface of the crystals when they were immersed in water.

The three types of crystals are shown in figure 2.1 . 
Table 2.3

\section{Analysis of MgO Polycrystals}

Impurity

$\mathrm{Ca}$

ST

$\mathrm{Fe}$

T

AI

FT

$\mathrm{Si}$

T

$\mathrm{Pb}$

T- ST

$\mathrm{ST}=$ strong trace

B

FT

$\mathrm{T}=$ trace

$\mathrm{V}$

$\mathrm{N}$

$$
F T=\text { faint trace }
$$

$\mathrm{Cu}$

ST

$\mathrm{VFT}=$ very faint trace

In

VFT

$N=$ not detected

Ti

N

$\mathrm{Mu}$

FT

Cr

FT

$\mathrm{Sn}$

FT

$\mathrm{Ni}$

$$
\text { VFT }
$$

Cd

VFT

Ag

T

Polycrystals supplied by Semi-Elements Inc. Analysis by the Defence Standards Iaboratories. 


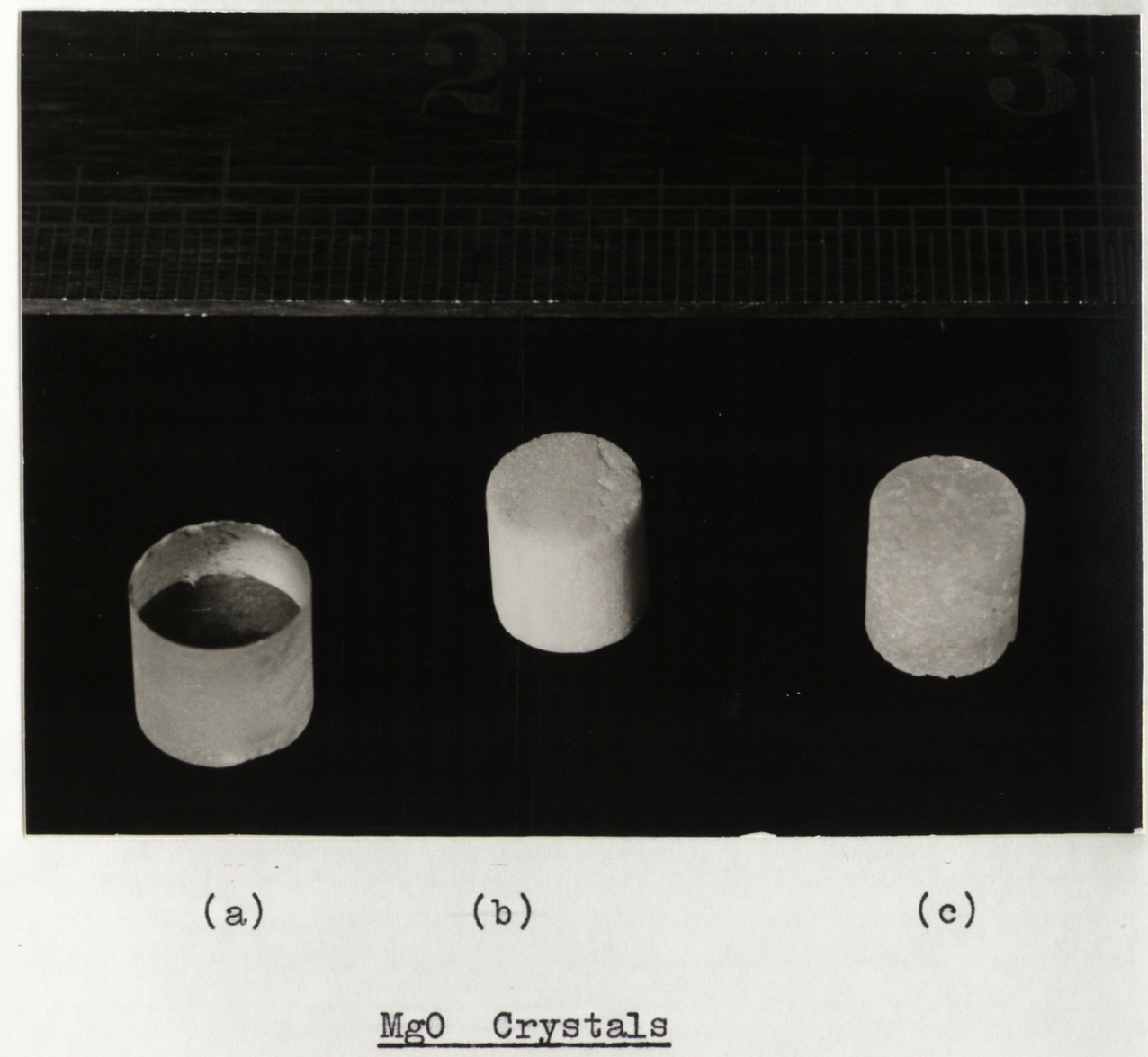

(a) Single crystal

(b) Polycrystal $0.1 \mathrm{~mm}$ grain size

(c) Polycrystal $1.0 \mathrm{~mm}$ grain size 


\section{REFERENCES Chap. 2}

(1) P. G. Shewmon, "Diffusion in Solids" p 145, McGraw-Hill (1963)

(2) B. J. Wuensch, Private communication.

(3) B. J. Wuensch \& T. Vasilos, J. of Chem. Phys., 36, 2917 (1962)

(4) D. H. Bowen, "6th Metallurgical Conference, Saclay" p 151, Presses Universitaires de France, (Paris) (1962).

(5) B. Hendergon, Phil. Mag., 2, 153 (1964).

(6) D. H. Bowen \& F.J.P. Clarke, Phil. Mag., ㅇ, 1257 (1963) 


\section{GENERAL METHOD}

Radioactive Tracer Technique.

The use of radioactive isotopes is the most convenient method of studying the diffusion of impurities at near-zero concentrations. Even though the ratio of the diffusion coefficients for different isotopes of the same chemical species can be as great as the ratio of the square roots of their mass numbers ${ }^{1}$, this variation is negligible in most cases. Thus it is permissible to take the diffusion coefficients found by radioactive isotopes as applicable to other atoms of the same chemical species.

Some of the advantages of the technique are that the impurity can be easily detected by virtue of its radiations, using the usual methods of G.M. or scintillation counting or autoradiography. All of these methods are extremely sensitive. For example, 100 counts per second from carrier-free ${ }^{45} \mathrm{Ca}$ detected with a G.M. counter corresponds to a mass of $2.5 \times 10^{-15} \mathrm{gms}$. Lastly each radioactive isotope has a characteristic radiation and a specific half-life so that the tracer can be followed unambiguously.

If a radioactive tracer is to be useful as a tracer in diffusion, it should possess certain properties:-

a) its half-life should be sufficiently long. This is because diffusion runs, especially at low temperatures, sometimes take several months to complet 
b) its specific activity should be high, so that small quantities of the impurity can be detected easily.

c) the radiation itself should be of a type which is easily detectable.

d) if possible, its production should be easy. of the several detecting methods available, a photographic one was chosen for the present work. The motion of the calcium through the magnesium oxide was followed by autoradiography. One advantage of this method is that it is very simple and no elaborate equipment is required. The other most often employed method of determining penetration profiles is by serially sectioning through the diffusion zone and subjecting each of the layers removed to radioactive assay. In the present case, because of the very small diffusion rates operating, the peretrations involved are small so that section removal by precision grinding would have to be adopted. However, because $\mathrm{MgO}$ cleaves very readily, this method might be more difficult than usual. Of much greater importance is the fact that the autoradiographic method yields individual coefficients from different regions of the same crystal, whereas serial sectioning gives only an average diffusion coefficient. This last point is important as it has been suggested ${ }^{2}$ that the MgO at present available is inhomogeneous because of segregated impurities. 
Solutions of the Diffusion Equation.

When the distribution of the tracer in the specimen has been determined, the diffusion coefficient operating has to be found. The starting point for evaluating diffusion coefficients is Fick's second law:

$$
\frac{d C}{d t}=\frac{d}{d x}\left(D \frac{d C}{d x}\right)
$$

where

$$
\begin{aligned}
& D=\text { diffusion coefficient } \\
& C=\text { concentration of the impurity } \\
& x=\text { penetration distance } \\
& t=\text { diffusion time }
\end{aligned}
$$

This type of differential equation is very common in many branches of physics (eg. heat flow and potential theory) and many solutions specially applicable to diffusion have been evaluated ${ }^{3,4}$.

If $D$ does not vary with concentration then eqn. 3.1 can be written:

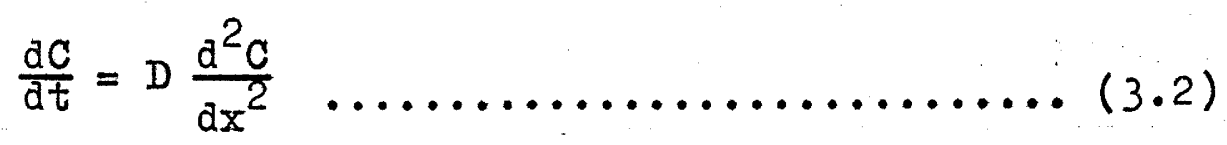

As with any differential equation a unique solution cannot be found until the boundary conditions are specified.

For a thin surface source diffusing in a sandwich type geometry, the boundary conditions can be written:

$$
\begin{array}{ll}
|x|>0 & c \rightarrow 0 \text { as } t \rightarrow 0 \\
x=0 & c \rightarrow \infty \text { as } t \rightarrow 0
\end{array}
$$

As can be verified by direct substitution in eqn. 3.2 , the solution in this case is: 


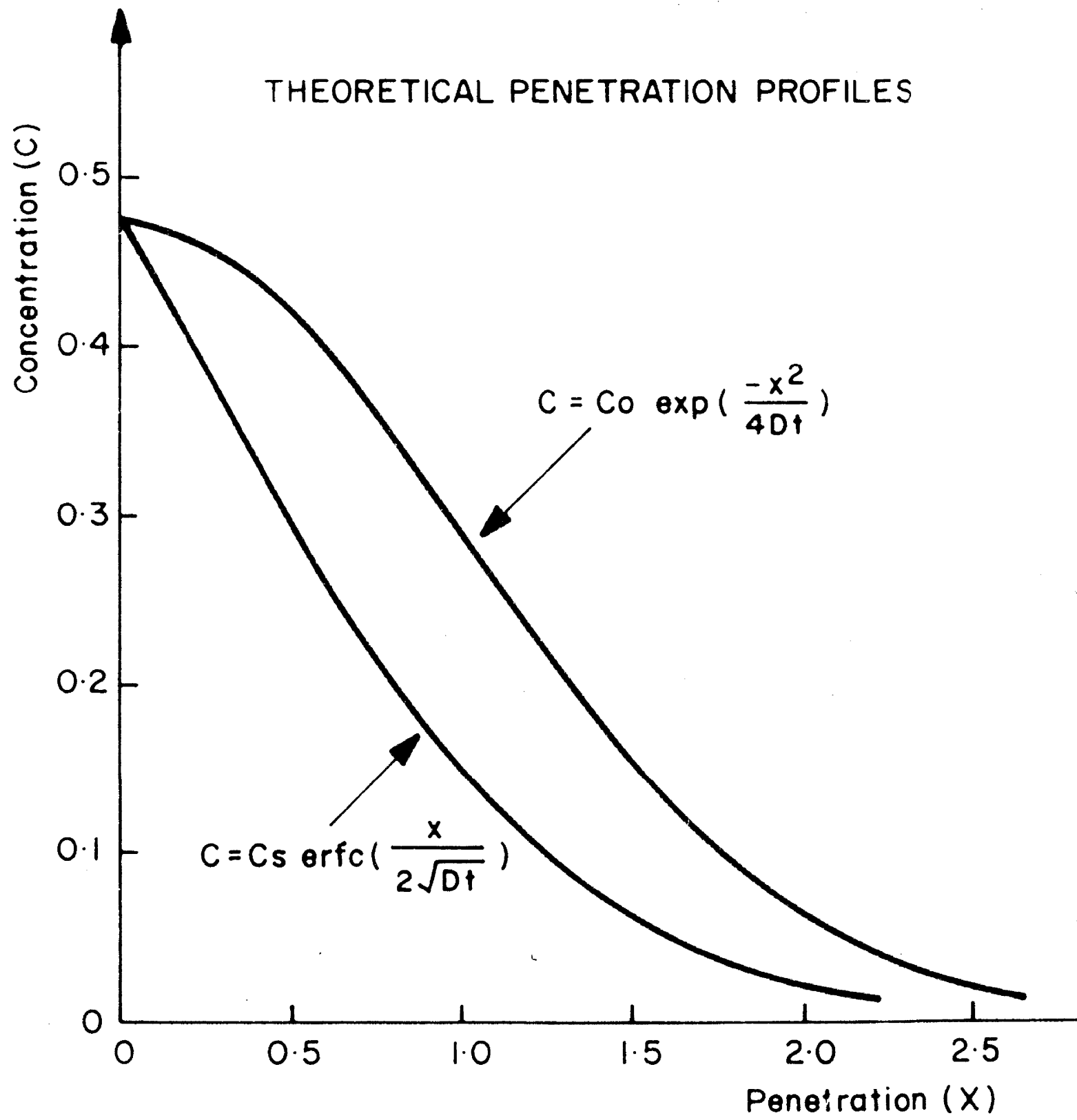

FIG. 3.1 


$$
C=(\alpha / 2 \sqrt{\pi D t}) \exp \left(-x^{2} / 4 D t\right) \ldots \ldots \ldots \ldots \ldots(3.3)
$$

where $\alpha$ is the total amount of surface deposit. The $c$ vs. $x$ profile of this equation is given in fig.3.1. Hereafter equation 3.3 will be referred to as "the Gaussian solution".

A consequence of this solution is that the total amount of diffusing impurity or solute remains fixed because:

$$
\int_{-\infty}^{\infty} c(x, t) d x=\alpha
$$

Eqne 3.3 can be written in the form:

$$
C=c_{0} \exp \left(-x^{2} / 4 D t\right) \ldots \ldots \ldots \ldots \ldots \ldots(3.4)
$$

Taking logs:

$$
I n C-I n C_{0}=-x^{2} / 4 D t
$$

It is seen that the graph of InC vs. $x^{2}$ is a straight line, the slope of which is $-1 / 4 \mathrm{Dt}$. If the diffusion is carried out for a known time, $D$ is then easily determined. It has been pointed out ${ }^{5}$ that some precautions have to be taken if this solution is to be applied. The deposited layer (d) should be thin because at $t=0$ it is assumed to be located entirely at $x=0$. Mathematically this can be written $a \ll 2 \sqrt{D t}$. Also, it is assumed that all of the initial deposit $\alpha$ participates in the diffusion process from $t=0$. In other words, the solubility of the impurity in the solvent should be large so that the total amount $\propto$, can go into solution, and it should do so in a time which is short compared to the total annealing time. It is usual to take this initial period to be no greater than $1 \%$ of the total annealing time. 
If the solubility is small or the deposited layer thick, the distribution will approximate that which occurs for diffusion from a constant source. Physically, the concentration of the impurity at the surface will reach the solubility limit of the solvent very rapidly and more solute can dissolve only when this has diffused into the interior of the solvent. Thus if there is an ample supply of solute on the surface the amount of solute just inside the surface will not drop below the solubility limit during the whole diffusion annealing. Thus the conditions for diffusion from a constant source will be satisfied.

The boundary conditions for this can be written:

$$
c=0 \text { at } t=0 \text { for } 0<x<\infty
$$

and $c=c_{s}$ at $x=x_{s}$ for $0<t<\infty$

and the corresponding solution of eqn. 3.2 is:

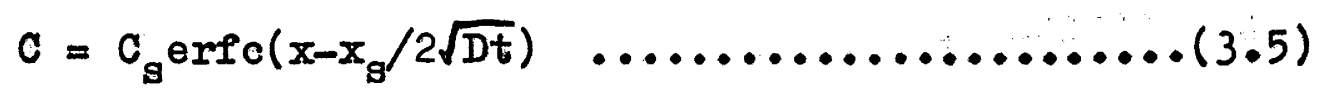

where $C_{f}$ is the solubility limit of the primary phase and $x_{\mathrm{g}}$ is the thickness of the zone of surface phases where the concentration is greater than the solubility limit. The applicability of this solution assumes that $x_{g}$ is independent of time. In the present work it has been found that the surface zone is undetectably small, so that $x_{\mathrm{g}}=0$.

The $C$ vs. $x$ profile of this equation for $x_{s}=0$ is given in fig. 3.1. Hereafter equation 3.5 will be referred to as "the error-function solution". 
One way to find $D$ from this solution would be to plot $\operatorname{erfc}^{-1}\left(\mathrm{C} / \mathrm{C}_{\mathrm{g}}\right) \mathrm{vs}$. $\mathrm{x}$. The slope of this straight line graph is $1 / 2 \sqrt{D t}$ which determines $D$.

The difficulty with this solution is that it relies on the value of $\mathrm{C}_{\mathbf{S}}$ which has to be estimated from the graph of $C$ vs $x$ and if $C_{s}$ is inaccurate, then the whole calculation is effected. A method has to be found which gives $D$ and is independent of surface conditions.

Differentiating eqn. 3.5 and putting $x_{g}=0$ $\mathrm{d} C / \mathrm{dx}=-C_{\mathrm{s}} / \sqrt{\pi D t} \exp \left(-\mathrm{x}^{2} / 4 \mathrm{Dt}\right) \ldots \ldots \ldots \ldots(3.6)$ (Cf. thin surface source solution, eqn. 3.3)

By plotting $\ln (d C / d x)$ vs. $x^{2}$, a straight line graph with a slope $-1 / 4 D t$ is obtained, thus $D$ can be determined by a method independent of surface conditions, (since $x_{g}=0$ ).

The experimental scatter of the initial data, however, will be greatly increased because the slope, $\mathrm{dc} / \mathrm{dx}$, has to be evaluated between adjacent points, therefore making it possible to apply eqn. 3.6 to only a few selected cases. This effect is shown in figure 3.2. Although both examples have reasonably "smooth" C vs. $x$ and InC vs. $x^{2}$ graphs, only example (a) has a $\ln (\mathrm{dc} / \mathrm{dx})$ vs. $\mathrm{x}^{2}$ graph resembling a straight line. The $\ln (\mathrm{dc} / \mathrm{dx}$ vg. $x^{2}$ graph for example (b) shows a much larger scatter and no trend in the slope. Although the scatter in example (a) is still very large, it is the best straight line graph obtained by this method in the present work. 
EXHEKIMENIAL PENETRATION PROFILES
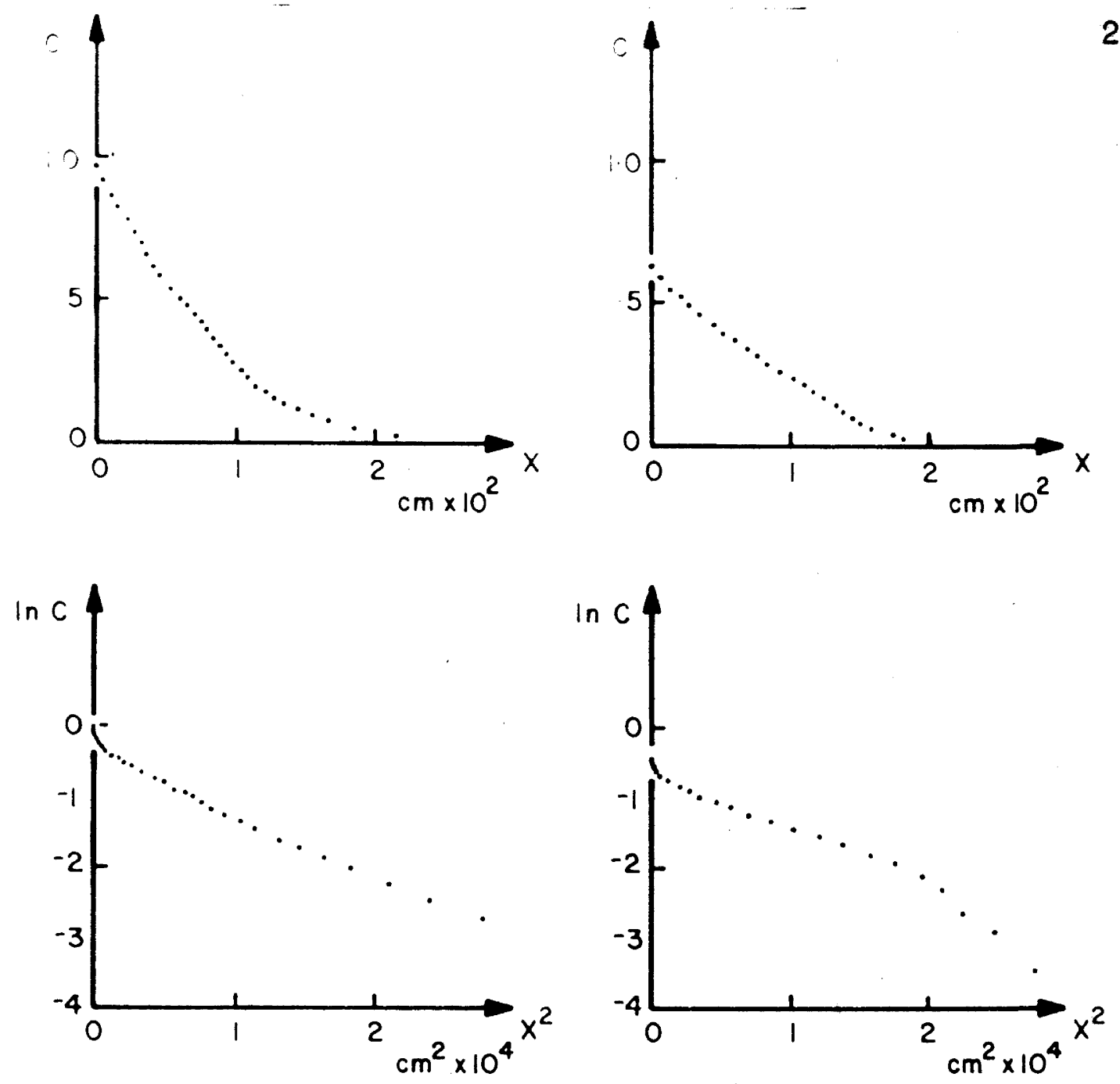

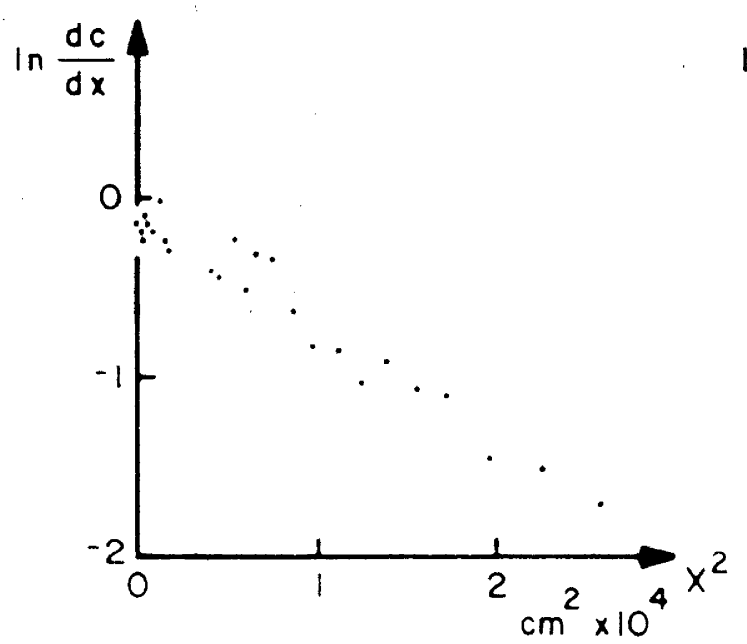

a)

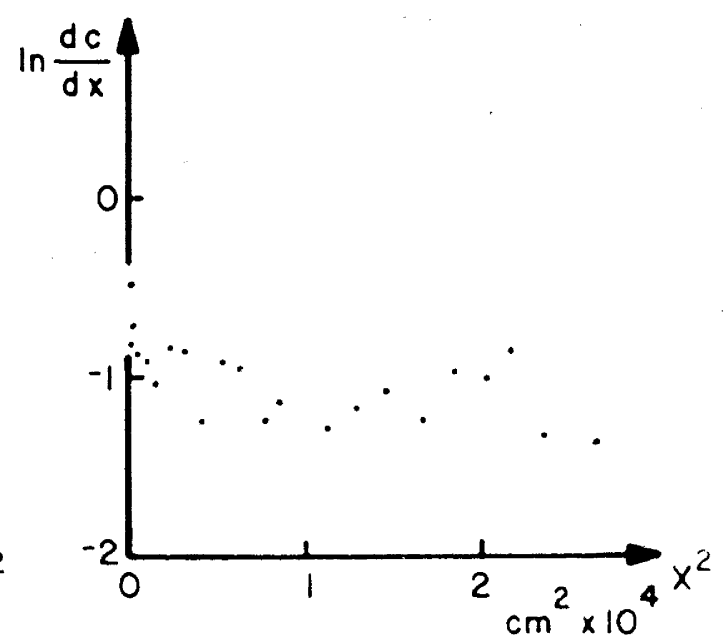

(b)

FIG 32 
It has been reported ${ }^{6}$ that the solubility of calcium in magnesium oxide is very small and this combined with the fact that it is difficult to deposit a very small quantity of calcium indicates that the error function solution should be applied in this case (see appendix 3.1). However, it is possible to apply the more convenient Gausgian solution for the actual evaluation of the associated diffusion coefficient and to subsequently introduce a correction factor ${ }^{7}$.

If the diffusion coefficient supposediy calculated by applying the error function solution is denoted by $D_{c}$ and the diffusion coefficient calculated by applying the Gaussian solution is $D_{a}$, it is possible to evaluate the ratio $D_{c} / D_{a}$ as a function of $x / \sqrt{D_{c} t}$. In this way it is found that:

$$
\frac{D_{c}}{D_{c}}=\frac{2}{\sqrt{\pi}} \cdot \frac{\sqrt{D_{c} t}}{x} \cdot \frac{\exp \left(-x^{2} / 4 D_{c} t\right)}{\operatorname{erfc}\left(x / 2 \sqrt{D_{c} t}\right)} \ldots \ldots \ldots(3.7)
$$

This equation is plotted in fig. 3.3 .

Two interesting consequences of this analysis are that as $x$ becomes very large the two solutions become identical and that if $D$ is evaluated using the Gaussian solution, when in fact the error function should apply, then the fractional error in the apparent value of $D$ will be constant, providing the same value of $x / \sqrt{D t}$ operates in every case.

In the present work, all diffusion coefficients were evaluated using the Gausgian solution, between limits for $x$ 


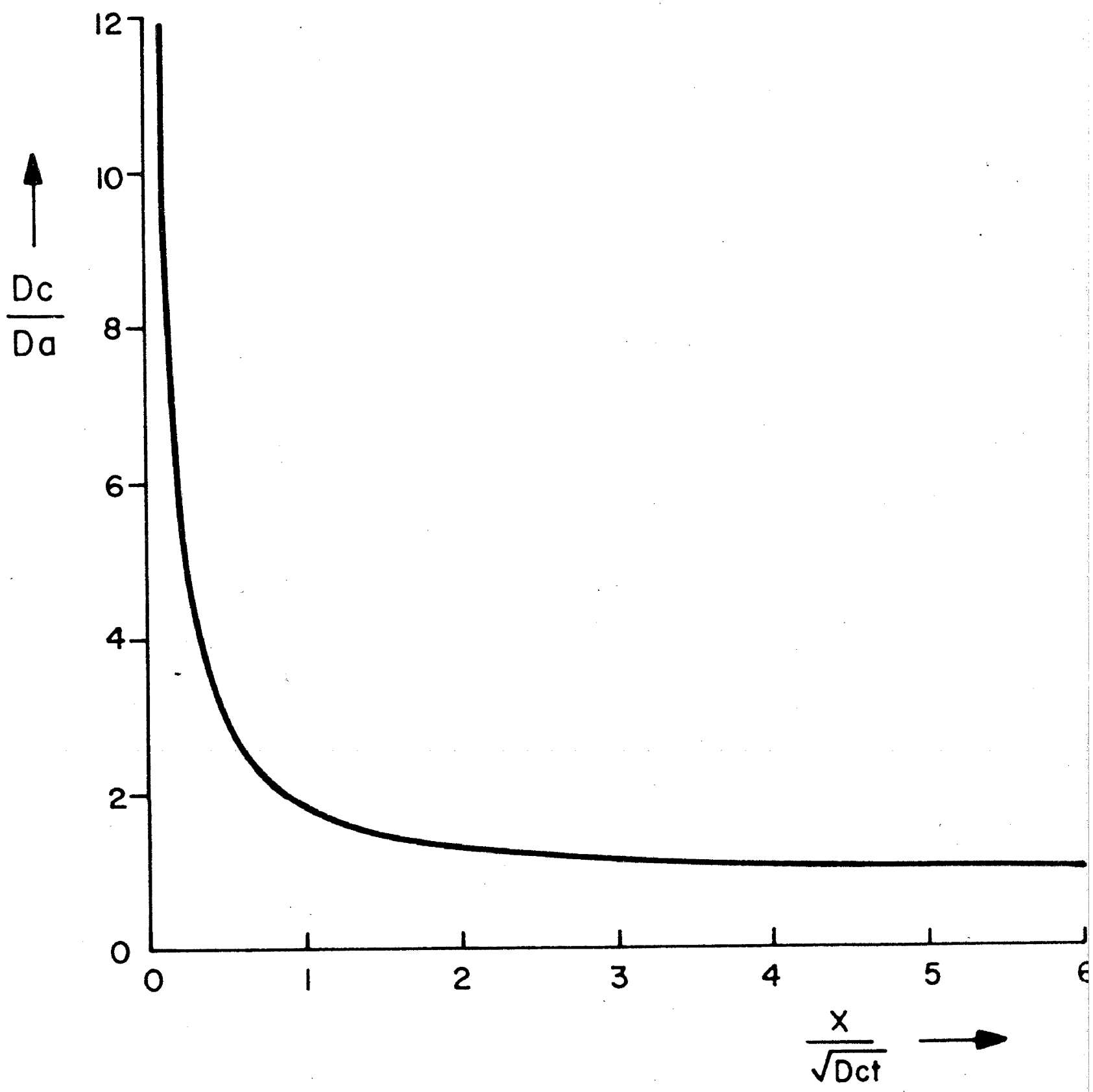

FIG. $3 \cdot 3$ 
of $\sqrt{D t}$ and $3 \sqrt{D t}$. So that in this case, the effective value of $D_{c} / D_{a}$ was calculated by numerical intergration to be approximately 1.5 . Thus even if all the penetration profiles are of the error function type, the Gaussian solution can still be applied because then all the D's will be too low by a factor of $50 \%$. Because the temperature dependence of the diffusion coefficient follows the law:

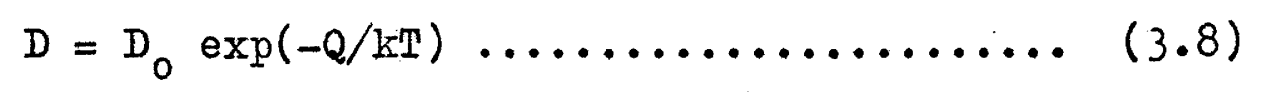

where $Q=$ activation energy

$$
\begin{aligned}
& D_{0}=\text { frequency factor } \\
& k=\text { Boltzmann's constant } \\
& T=\text { absolute temperature }
\end{aligned}
$$

the activation energy, which is the most important parameter, is not effected by this procedure. Only $D_{0}$ will be too small but may be corrected for by applying the calculated value of $D_{c} / D_{a}$ which is operating. Such a procedure gives an accurate value for the activation energy but the frequency factor, as is common in this type of work, will be subject to fairly large uncertainties.

\section{Appendix 3.1}

Calculation of Minimum Surface Deposit of Calcium Required for Error-Function Solution to Apply.

The integral over $x$ from 0 to $\infty$ of eqn. 3.5 represents the total amount $(s)$ of impurity which has gone into solution during the annealing time. 
Thus: $\quad s=\int_{0}^{\infty} C_{s} \operatorname{erfc}(x / 2 \sqrt{D t}) d x$

Now if $\mathrm{m}$ is the total amount of impurity deposited on the surface then $m$ must be greater than $s$, if the errorfunction solution is to be applicable. In other words, all the impurity has not gone into solution during the annealing. Now, $\int \operatorname{erf}(x) d x=\operatorname{xerf}(x)+\frac{1}{\sqrt{\pi}} \exp \left(-x^{2}\right)+$ const. ... (3.10) Putting $u=\frac{x}{2 \sqrt{D t}}$ in eqn. 3.9 :

$$
s=C_{s} 2 \sqrt{D t} \int_{0}^{\infty}(1-e r f u) d u
$$

Applying eqn. 3.10:

$$
\begin{aligned}
\mathbf{s} & =c_{\mathrm{g}} 2 \sqrt{D t}\left[u-\operatorname{uerf}(u)-\frac{\left.1 \exp \left(-u^{2}\right)\right]_{0}^{\infty}}{\sqrt{\pi}}\right. \\
& =c_{s} 2 \sqrt{D t}\left(\infty-0-\infty+0-\frac{1}{\sqrt{\pi}} \cdot 0+\frac{1}{\sqrt{\pi}}\right) \\
& =c_{g} \frac{2 D t}{\sqrt{\pi}} \ldots \ldots \ldots \ldots \ldots \ldots \ldots \ldots \ldots \ldots \ldots \ldots \ldots
\end{aligned}
$$

A solid solubility of calcium oxide in magnesium oxide as high as 1 wt.\% at $1600^{\circ} \mathrm{C}$ has recently been reported ${ }^{8}$. By extrapolation it is estimated that the solubility at $1000^{\circ} \mathrm{C}$ would be 0.01 wt.\%. By considering a crystal of unit crosssection the solubility limit, $C_{s}$, of calcium in magnesium oxide can be expressed in terms of $\mathrm{gm} / \mathrm{cm}$.

Taking two typical examples:

$\begin{array}{lll}\text { Temperature }\left({ }^{0} \mathrm{C}\right) & 960 & 1600 \\ \text { Diff. coef. (cm } / \mathrm{sec}) & 2 \times 10^{-14} & 4 \times 10^{-11} \\ \text { Time (sec) } & 11 \times 10^{6} & 6 \times 10^{5} \\ \text { Sol. Iimit (wt.\%) } & 0.01 & 1.0 \\ \text { Sol. Iimit (gm/cm) } & 3.65 \times 10^{-4} & 3.65 \times 10^{-2} \\ \text { s, amount of impurity } & 1.9 \times 10^{-7} & 2.0 \times 10^{-4}\end{array}$
in solution (gm) 
The total amount of deposit, $m$, was approximately $2 \times 10^{-5}$ gm in each case so that, according to the solubility data, the Gaussian solution should apply at the higher temperatures while the error-function solution is applicable at the lower ones. However, from the penetration profiles it was found that the error-function solution was operating in practically all cases. This evidence indicates that, even at the higher temperatures, the amount of impurity deposited was approximately equal to the total amount which could go into solution so that the reported solubility of $1 \%$ at $1600^{\circ} \mathrm{C}$ appears to be ten times too high. 


\section{REFERENCES Chap. 3 .}
(1) J. G. Mullen, Phys. Rev., 121, 1649 (1961).
(2) F. J. P. Clarke, Private communication.
(3) J. Crank, "The Mathematics of Diffusion", O.J.P. (1956).
(4) W. Jost, "Diffusion in Solids, Iiquids and Gases", Academic Press (1960).

(5) R. Sh. Malkovich, Soviet Physics - Solid State, 1, 548 (1959)

(6) F. Trojer \& K. Konopicky, Radex Rundschau, 4, 161 (1949).

(7) A. J. Mortlock, Acta Met., 12, 675 (1964).

(8) R. C. Doman, J. B. Barr, R. N. McNally \& A. M. Alper, J. Am. Ceram. Soc., 46, 313 (1963). 


\section{EXPERIMENTAL DETAIL}

\section{Radioactive Tracer}

The tracer chosen for the present work was ${ }^{45} \mathrm{Ca}$ which emits a $\beta^{-}$of $0.25 \mathrm{MeV}$ and has no other radiations. For autoradiography soft radiations are more suitable than hard radiations. Firstly, the less energetic particles are more likely to be stopped by the emulgion and so produce a stronger image, and secondly, their range in the specimen will be smaller so that better photographic resolution will be possible.

The calcium was received as calcium chloride solution with a specific activity of $2.5 \mathrm{c}{ }^{45} \mathrm{Ca} / \mathrm{gmCa}$. The absorbtion spectrum immediately after arrival and 43 days later was measured with a geiger counter and the results are shown in figure 4.1. It can be seen that the ${ }^{45} \mathrm{Ca}$ contrined some $\gamma-$ ray activity upon arrival but this disappeared after a very short time. The maxium energy of the $\beta$ 's corresponded to about $59 \mathrm{mgm} \mathrm{Al} / \mathrm{cm}^{2}$ which in turm corresponds to an energy of $0.25 \mathrm{Mev}$. The absorption spectrum after 43 days was normalised to the first one by counting a ${ }^{14} \mathrm{C}$ source in a known geometry on both days. After subtracting background in each case it was found that the $\beta$ activity had fallen to 83.9\% of the original value. This corresponds to a half life of 168 days which agrees quite well with the more accurate published figure of 164 days.

A $\gamma$ spectrum of the calcium was also carried out just after arrival and some time later. This showed that the $\gamma$ 


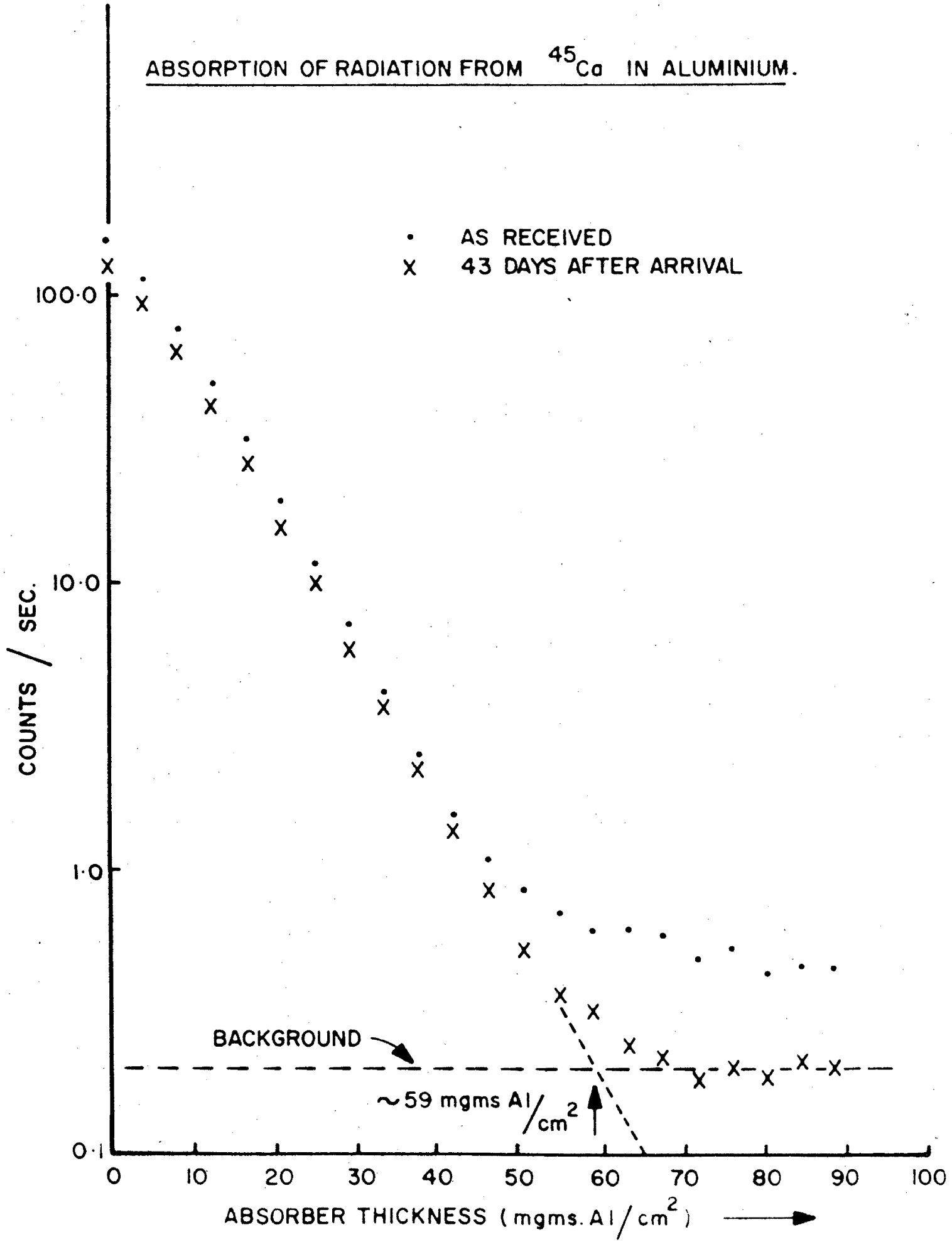

FIG. $4 \cdot 1$ 
activity was mainly due to ${ }^{47} \mathrm{Ca}$ and that this decayed to a negligible level as the half-life of 4.7 days predicts.

A similar analysis was carried out on ${ }^{63} \mathrm{Ni}$ as $\mathrm{NiCl}_{2}$ which was used in later experiments. It also confirmed the purity of the radioactive material used.

Preparation of Diffusion Couples

The MgO crystals were cleaved parallel to the end faces, producing two cylinders $\frac{1}{8} "$ high and $\frac{1}{4} "$ diameter and the cleaved faces were polished on diamond impregnated laps. The resultant faces were nearly optically flat, except for a slight curvature around the edge, as shown by the Newton's rings obtained when two such faces were placed in contact. The ${ }^{45} \mathrm{Ca}$ was deposited as calcium chloride solution with a microsyringe. The total volume of the deposit was of the order of $0.02 \mathrm{ml}$ containing approximately $2 \times 10^{-5} \mathrm{gm}$ of $\mathrm{CaCl}_{2}$. It was difficult to obtain an even surface deposit because of the surface tension of the water, but this was overcome to some extent by depositing several small drops. The surfaces were allowed to dry in air and the two halves were then bound together with platinum wire to form a sandwich.

Heat Treatment

The diffusion runs were carried out in a high purity alumina sheath, sealed, but containing air at atmospheric pressure. During the initial muns the air in the sheath was monitored but no evaporation of the deposit could be detected. 
In all, three types of electrical resistance furnaces together with different controls were used. The first was a nichrome-wound furnace controlled by an Alnor Pyrotroller at the lowest $\left(1050^{\circ} \mathrm{C}\right)$ temperatures. At the intermediate $\left(1050-1500^{\circ} \mathrm{C}\right)$ temperatures a Johnson Mathey, platinum-rhodium furnace, controlled by a Cambridge photoelectric controller, using a 10\% Pt.Rh. thermocouple, was employed. The Johnson Mathey and a Hereaus pure rhodium-wound furnace, controlled by a Leeds and Northrup "Rayotube", total radiation pyrometer. feeding into a Leeds and Northrup H type recorder-controller, were used at the highest $\left(1500-1700^{\circ} \mathrm{C}\right)$ temperatures. The Hereaus furnace had a very short life at the high temperatures and was therefore not found to be really satisfactory. Temperature Measurement

Temperatures were measured with a Pye potentiometer (cat. No. 7556) using a 10\% Pt.Bh. thermocouple at the lower temperatures and an 18\% Pt.Rh. thermocouple at the higher ones and these temperatures were continuously recorded. The tip of the thermocouple was in contact with the specimen and to ensure that the readings did not drift with changes in ambient temperature a constant temperature, electric cold junction (Sunvic type CJ1) was employed. To further ensure that the temperature readings were accurate, all thermocouples used were calibrated by the National Standards Iaboratory, Sydney and the Pye potentiometer used was checked against a 
Tinsley Vermier potentionmeter (type 4363F) which had an accuracy of $0.001 \%$ at $10 \mathrm{mV}$. The accuracies of the Pye potentiometer and the thermocouple calibration were $0.1 \%$ and $0.2 \%$ respectively, so that individual temperature readings were estimated to have an accuracy of $0.3 \%$.

This, of course, is not the accuracy to which the total diffusion run temperature can be measured. Because of the high temperatures involved; there was a fairly large on-off fluctuation in the temperature control and because of the long diffusion times some overall drift in the control temperature took place. At $1600^{\circ} \mathrm{C}$ for example, the effects of drift and the presence of an on-off cycle produce an uncertainty in the average annealing temperature of \pm 10 Celsius degrees. This $0.6 \%$ error in the temperature produces a $10 \%$ uncertainty in the diffusion coefficient.

Furnace Gradients

As it is difficult to obtain a constant temperature zone over any great length at the centre of the furnace, care has to be taken that a systematic error is not introduced because the temperature measured by the thermocouple is not the same as that of the diffusion zone. This was corrected for by measuring the temperature gradients in the furnaces and for most cases the difference between the measured temperature and that operating at the diffusion zone was estimated to be approximately 10 Celsius degrees. 
Annealing Time

The percentage errors involved in the measurement of time were very small because of the long diffusion times inrolved. The average heating-up and cooling-down time was half an hour and the duration of the diffusion runs was measured from when the specimen had reached $\frac{3}{4}$ of its final temperature to when it had cooled down to the same value. In this way it was possible to egtimate the total diffusing time to within an absolute accuracy of \pm 10 minutes. In a run lasting 5 days this means a fractional error of $0.14 \%$ while for a run of 2 months it is only $0.012 \%$.

Thrmal Expangion

The effects of the thermal expangion of the magnesium oxide should also be mentioned. The penetration distances are measured in centimetres at room temperature, whereas the actual penetration distance during diffusion was larger because of the thermal expangion of the cryatal. Therefore the diffusion coefficient should be increased by a factor $\left(I_{\text {temp }} / I_{\text {room }}\right)^{2}$ where $I_{\text {temp }}$ is the length of the penetration at the diffusion temperature and $I_{\text {room }}$ is the corresponding length at room temperature. For example, at $1200^{\circ} \mathrm{C}\left(I_{\text {temp }} / I_{\text {room }}\right)=1.0180$, and at $1800^{\circ} \mathrm{C}\left(I_{\text {temp }} / I_{\text {room }}\right)=1.0306$. This means that the corresponding diffugion coefficients have to be increased by $0.036 \%$ and $0.061 \%$. Because this correction is so small and because it has become conventional not to apply it, it has not been used in the present work. If it were taken 
account of, it would increase the activation energy by only $0.5 \%$ in the present case. This is negligible compared with the overall error limits oprating due to other causes. Determination of the Penetration Profile

After the heat treatment, a flat face was ground at right angles to the interface and parallel to the axis of the cylinders after they had been set in a polyester resin. This is carried out for two reasong. Firstly, it removes the surface layers through which diffusion could take place at a different rate than through the bulk of the specimen and secondly, it provides a longer, visible diffusion zone. Those runs in which the penetration was found to be very small were then cut at an angle to the original interface by a diamond slitting wheel as shown in fig. 4.2. This procedure effectively increases the apparent depth of penetration by a factor $1 / \sin \theta$, where $\theta$ is the angle between the cut and the original interface (see fig. $4.2(a)$ ). If $D_{\text {ang }}$ denotes the apperent diffusion coefficient found by angle-cutting and $D_{t}$ is the true diffusion coefficient operating, then:

$$
D_{t}=\sin ^{2} \theta D_{\text {ang }} \cdots \ldots(4.1)
$$

For example, at $5^{\circ}$ an increase in the apparent diffusion coefficient of approximately 100 is achieved.

After longtitudinal or angle-cutting the couples were carefully polished on 600 grit gxinding paper across the 


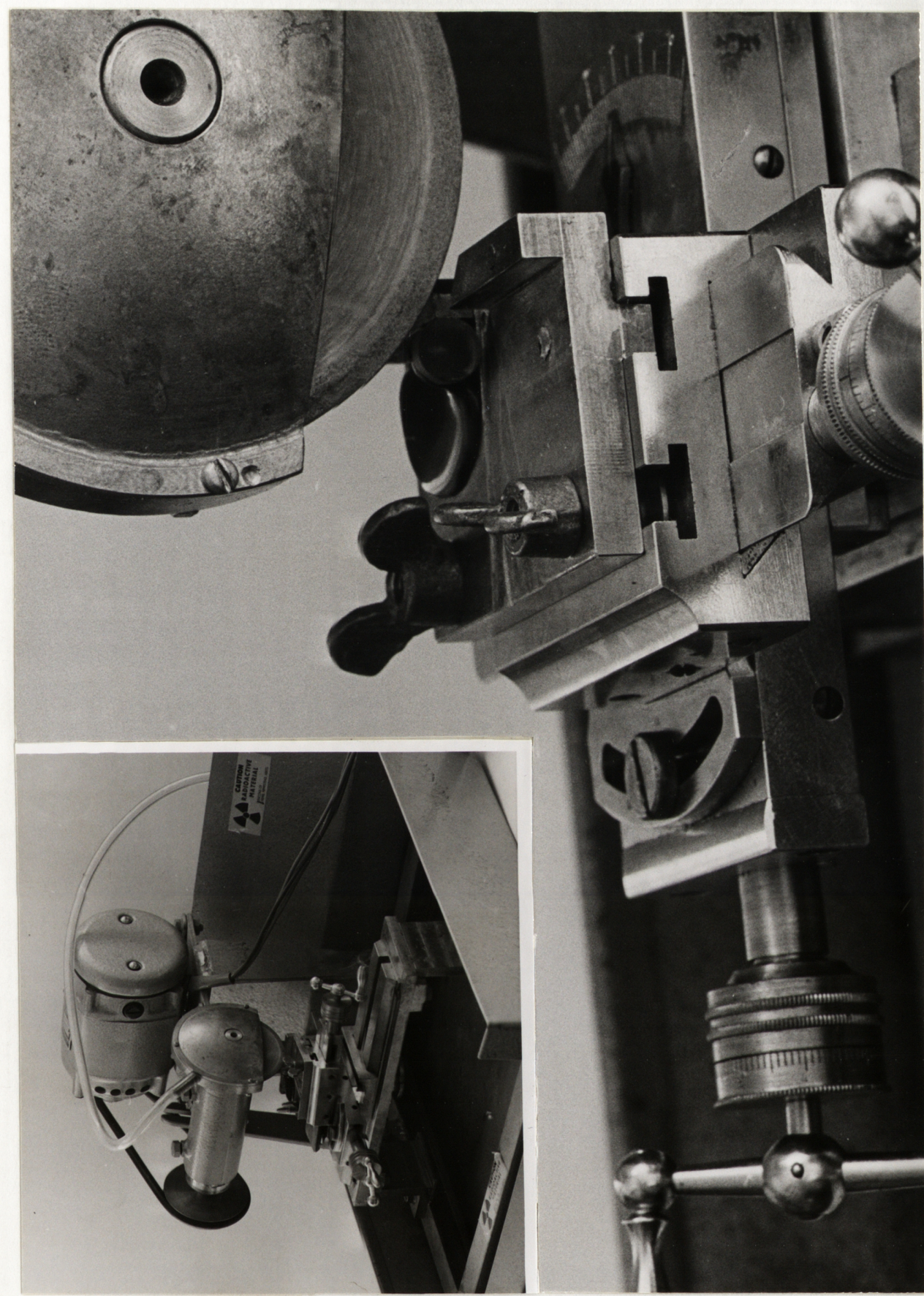

밈 


\section{MAGNIFICATION OF "ON-FILM" PENETRATION DISTANCE BY ANGLE-CUTTING.}

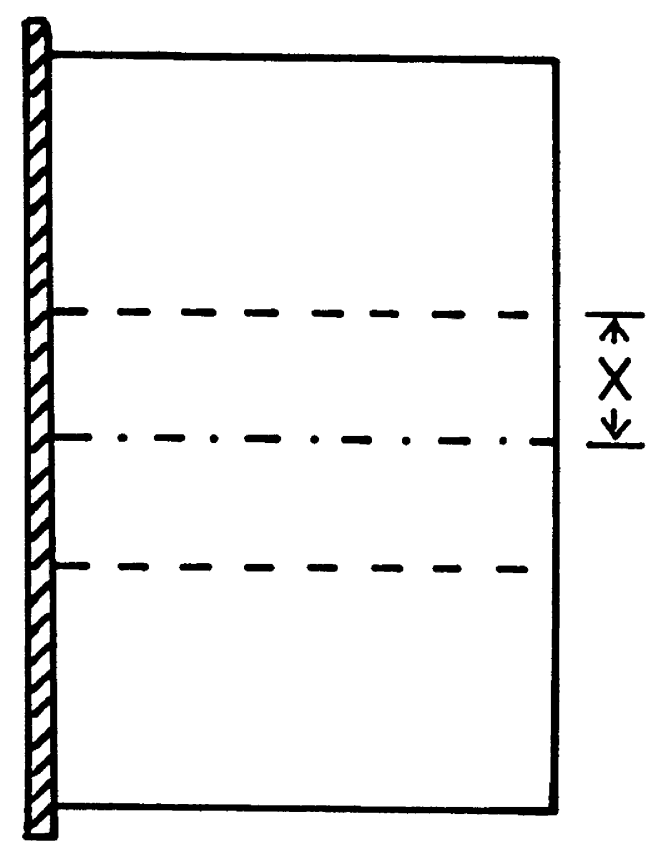

Longitudinal Sectioning Method.

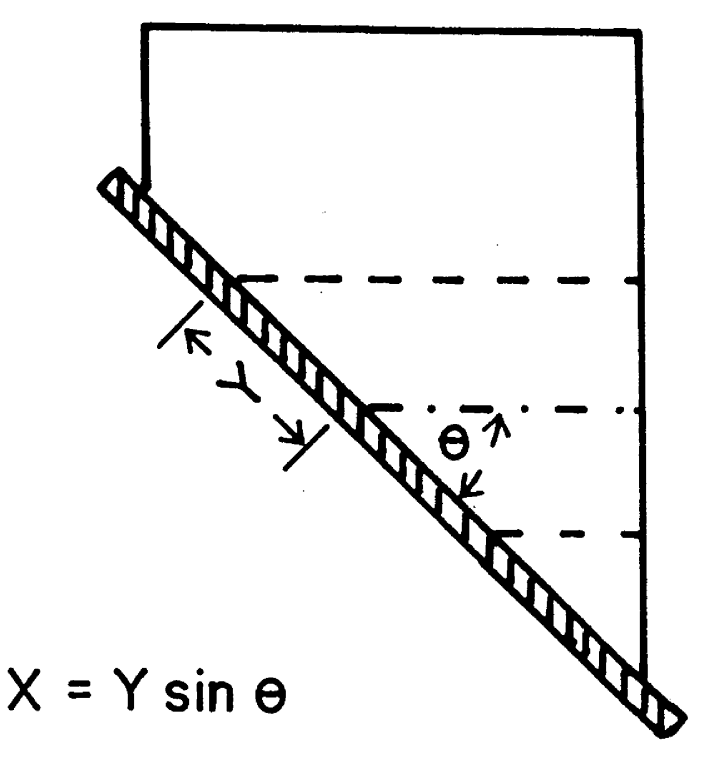

Angle-cutting Method.

$$
\begin{array}{ll}
\text { X-RAY FILM } \\
\cdots \cdots & \text { INITIAL DEPOSIT }
\end{array}
$$

FIG. 9.2 (a) 
direction of diffusion and then thoroughly washed to remove any stray radioactivity. After thorough drying they were placed in contact with some Kodak, Microtex X-ray film and exposed for an average of one wek. Typical autoradiographs are shown in figure 4.3 .

After processing, when it had dried, the film was scanned on a Hilger and Watts type I451 microphotometer, the output of which was recorded on a Ieeds and Northrup G type recorder. An effective on-film slit size of $0.01 \mathrm{~mm}$ by $0.5 \mathrm{~mm}$ was used, so that it was possible to obtain up to eight scans from a goods autoradiograph, thus producing sixteen diffusion coefficients from the one specimen. Four typical scans from different runs are shown in figure 4.4. The nominal scanning speed of the microphotometer was $0.25 \mathrm{~mm} / \mathrm{min}$ and that of the recorder chart 1 inch/ min. These speeds were measured accurately and it was found that the ratio of the distance on the film to distance on the chart was .009962 within an accuracy of $.16 \%$. The charts were then scanned on a two dimensional travelling microscope as show in figure 4.5. This instrument is capable of meausring to $0.01 \mathrm{~mm}$ and as it is only justified to measure penetration distances on the chart to $0.1 \mathrm{~mm}$ because of the grain size of the film no logs of accuracy occurs at this stage.

Resolution

Two precautions associated with this photographic technique which have to be taken into account are the resolution 


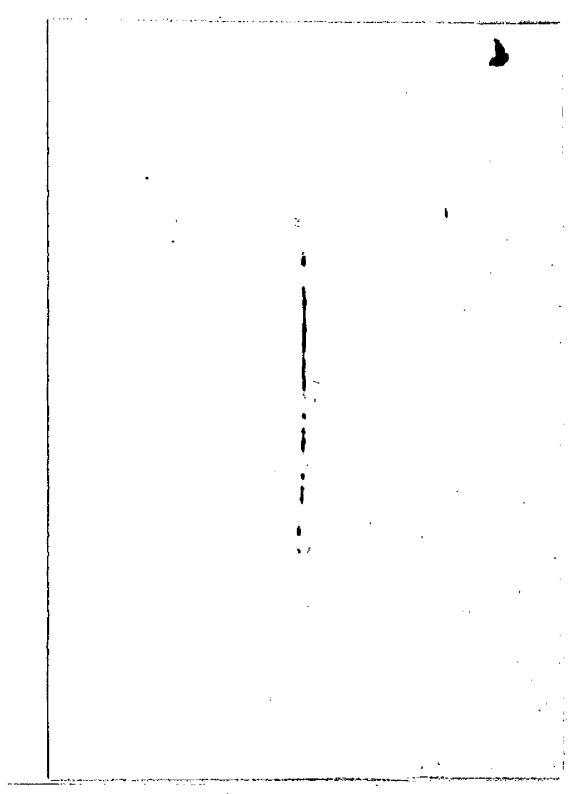

(a)

Undiffúsed

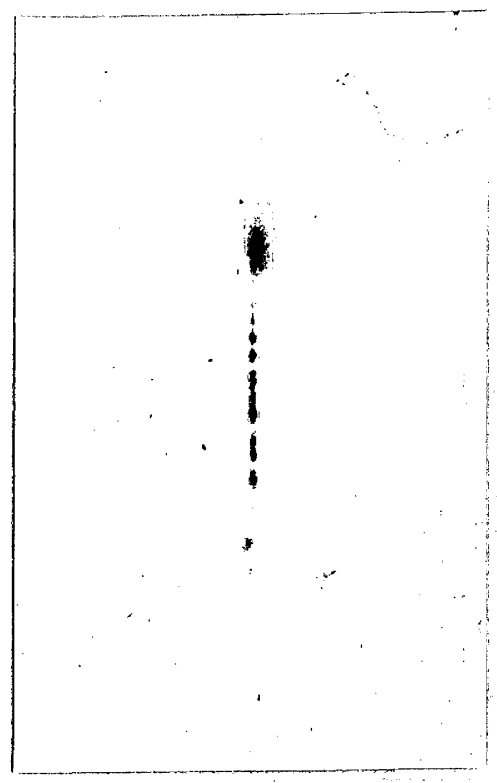

(b)

$857.0 \mathrm{hr}$ at $1382^{\circ} \mathrm{C}$ Magnification X10

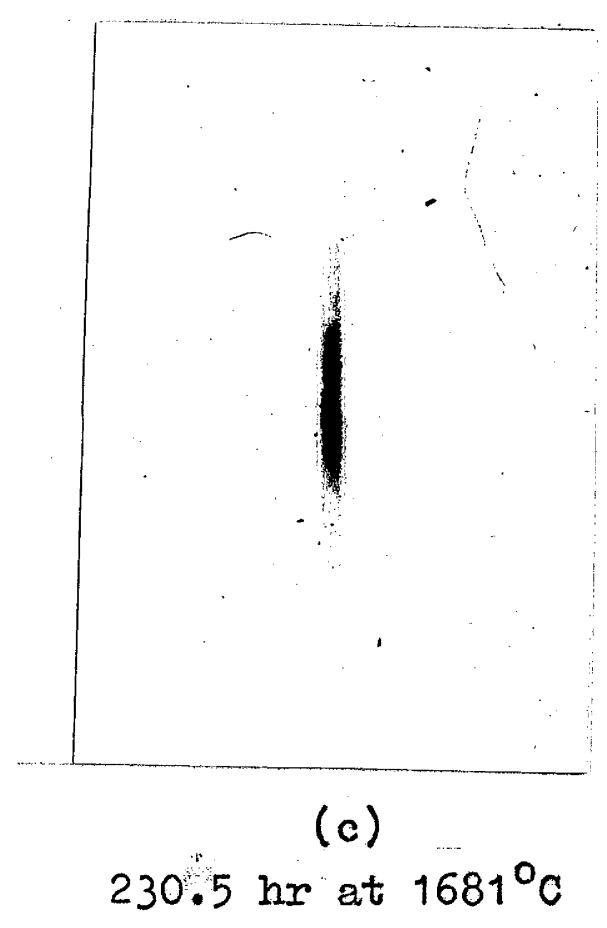

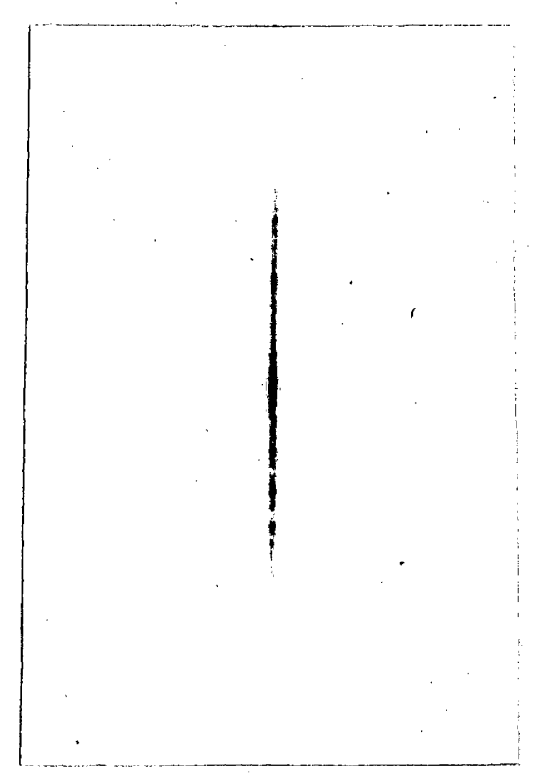

(d) $35.8 \mathrm{hr}$ at $1700^{\circ} \mathrm{C}$

\section{Fig. 4.3}


TYPICAL MICROPHOTOMETER SCANS OF AUTORADIOGRAPHS
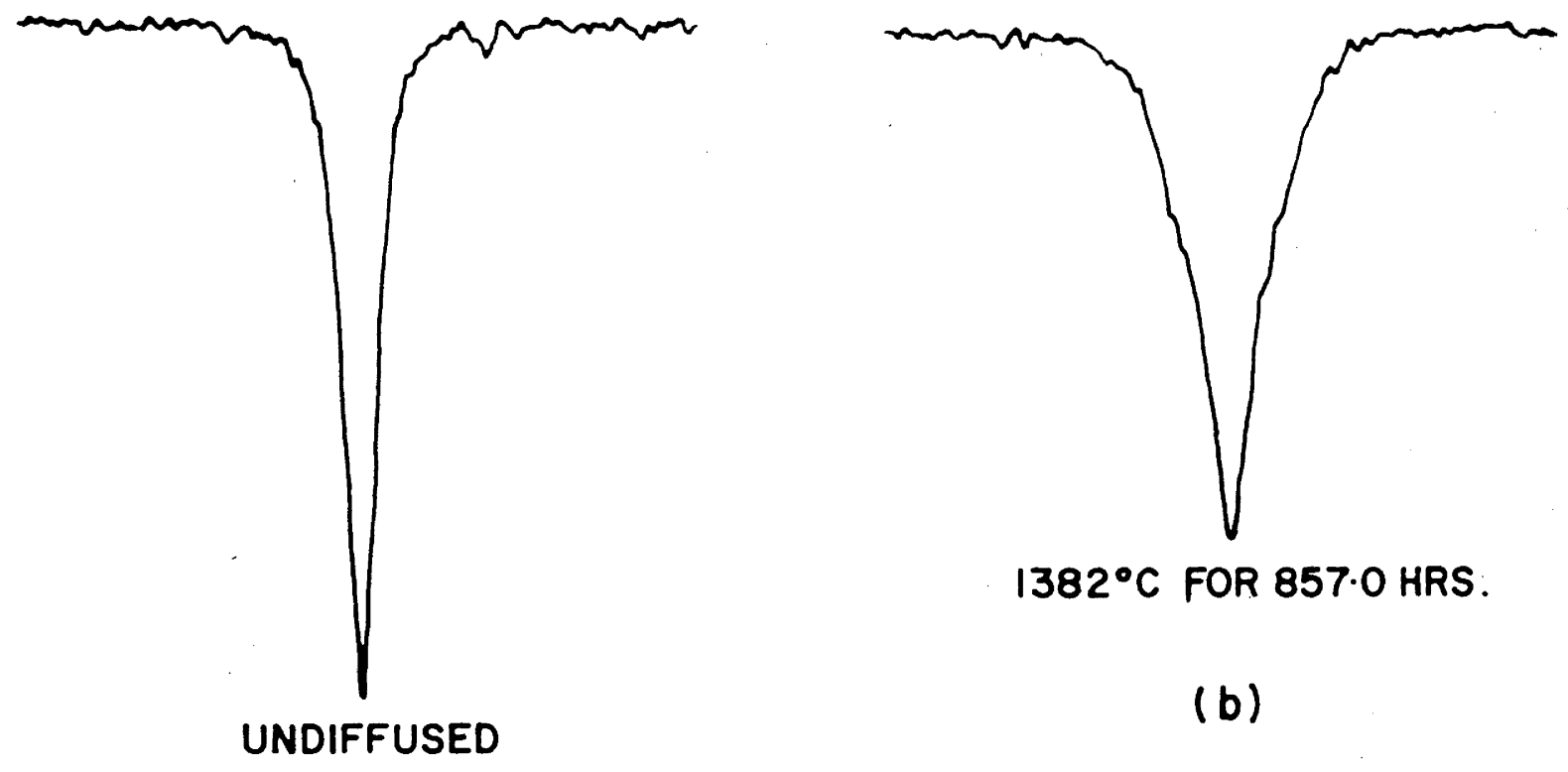

(a)

SCALE: $\rightarrow \begin{aligned} & 2 " \text { ON CHART } \\ & =5 \mathrm{~mm} \text { FILM }\end{aligned}$

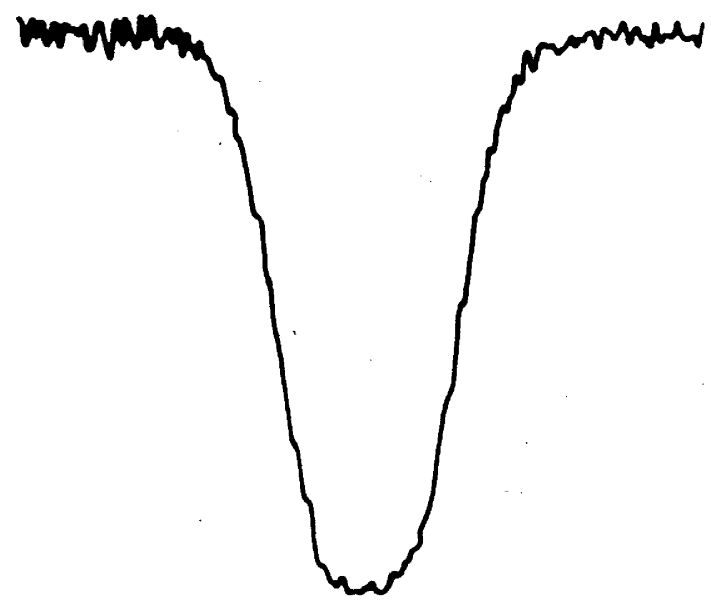

$1681^{\circ} \mathrm{C}$ FOR $230 \cdot 5 \mathrm{HRS}$.

(c)

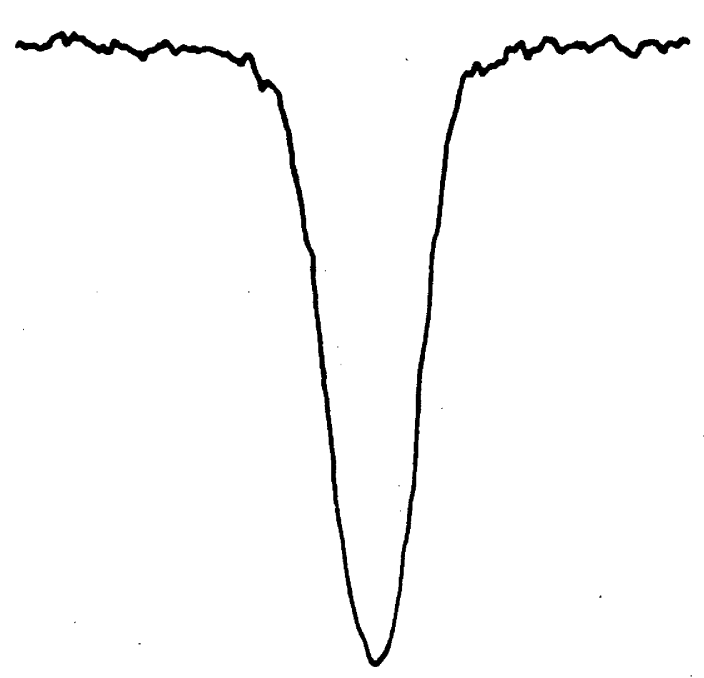

$1700^{\circ} \mathrm{C}$ FOR $35.8 \mathrm{HRS}$.

(d)

FIG. $4 \cdot 4$ 


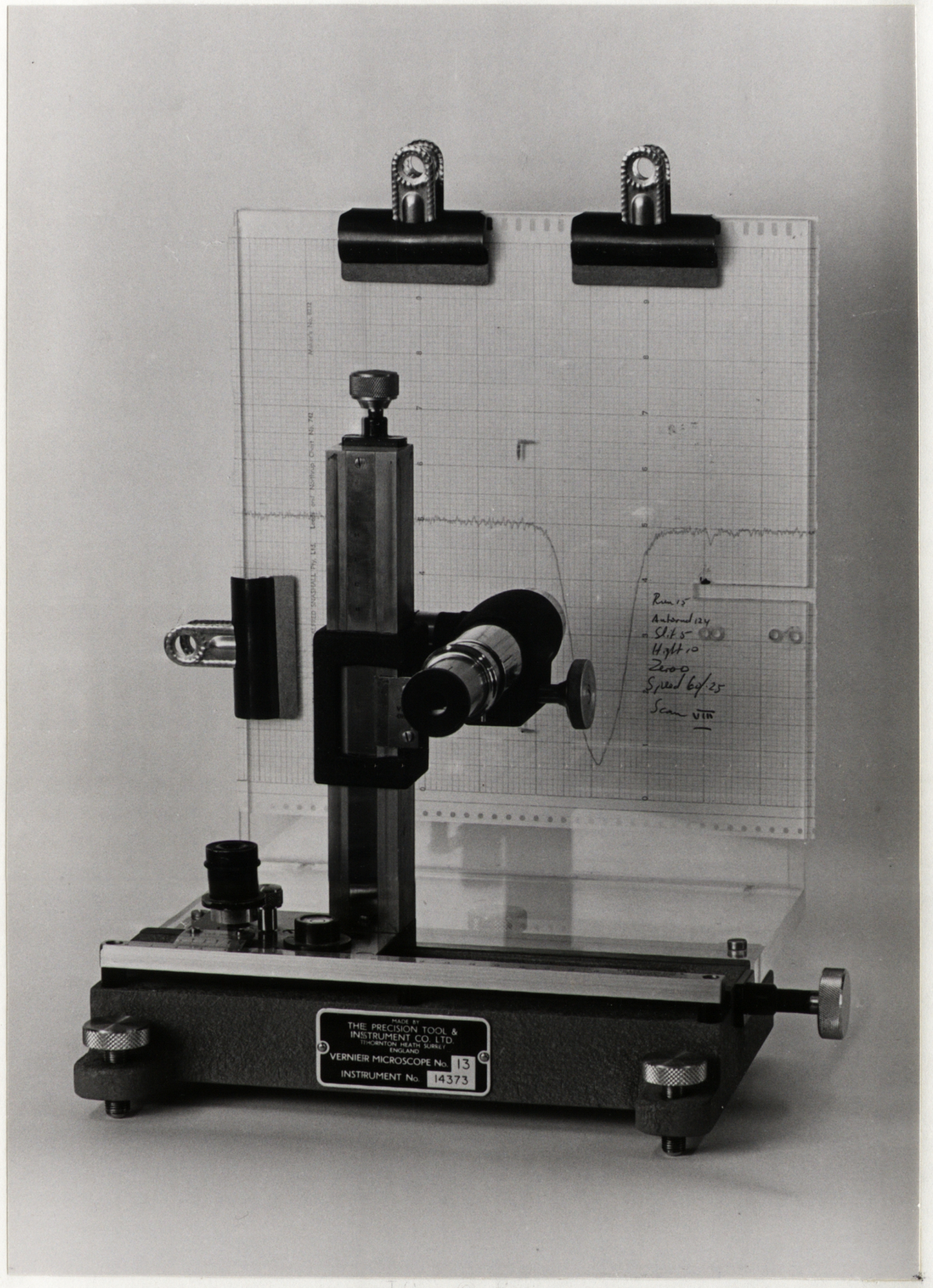

Fig. 4.5 
and the liniarity of the film. Figure 4.4(a) shows what is meant by "resolution". A thin film of radioactive calcium between two single crystals of magnesium oxide, placed on an X-ray film before any penetration has taken place, produces a broad image instlad of a line as thin as the deposit itself. This is because the $\beta$ particles from the calcium can penetrate the magnesium oxide and expose the film some distance away from the interface. After diffusion has taken place a similar situation will operate. If the diffusion zone is broken up into a large number of infinitely thin slices, each slice will act as a source of radiation and produce a broad line on the film just like the original deposit in the undiffused case. All these Iines then add up to produce the final apparent diffusion. Brown ${ }^{1}$ found that the undiffused profile had a Gaussian shape and therefore it was possible to evaluate an apparent Dt or (Dt) res by the methods given in the previous chapter, and then to correct for this resolution effect by simply subtracting the (Dt) res from the apparent Dt after diffusion or (Dt) app That is:

$$
(D t)_{\text {true }}=(D t)_{\text {app }}-(D t)_{\text {res }} \ldots \ldots \ldots \ldots \ldots(4.2)
$$

As shown in figure 4.6 , it was found that the undiffused scan had a Gaussian profile only to a first approximation, therefore the cases in which the ratio of (Dt) res to (Dt) app was greater than $10 \%$ could not be relied upon and angle-cutting had to be used to improve the resolution. (The figure of $10 \%$ was chosen 
42

UNDIFFUSED PROFILE
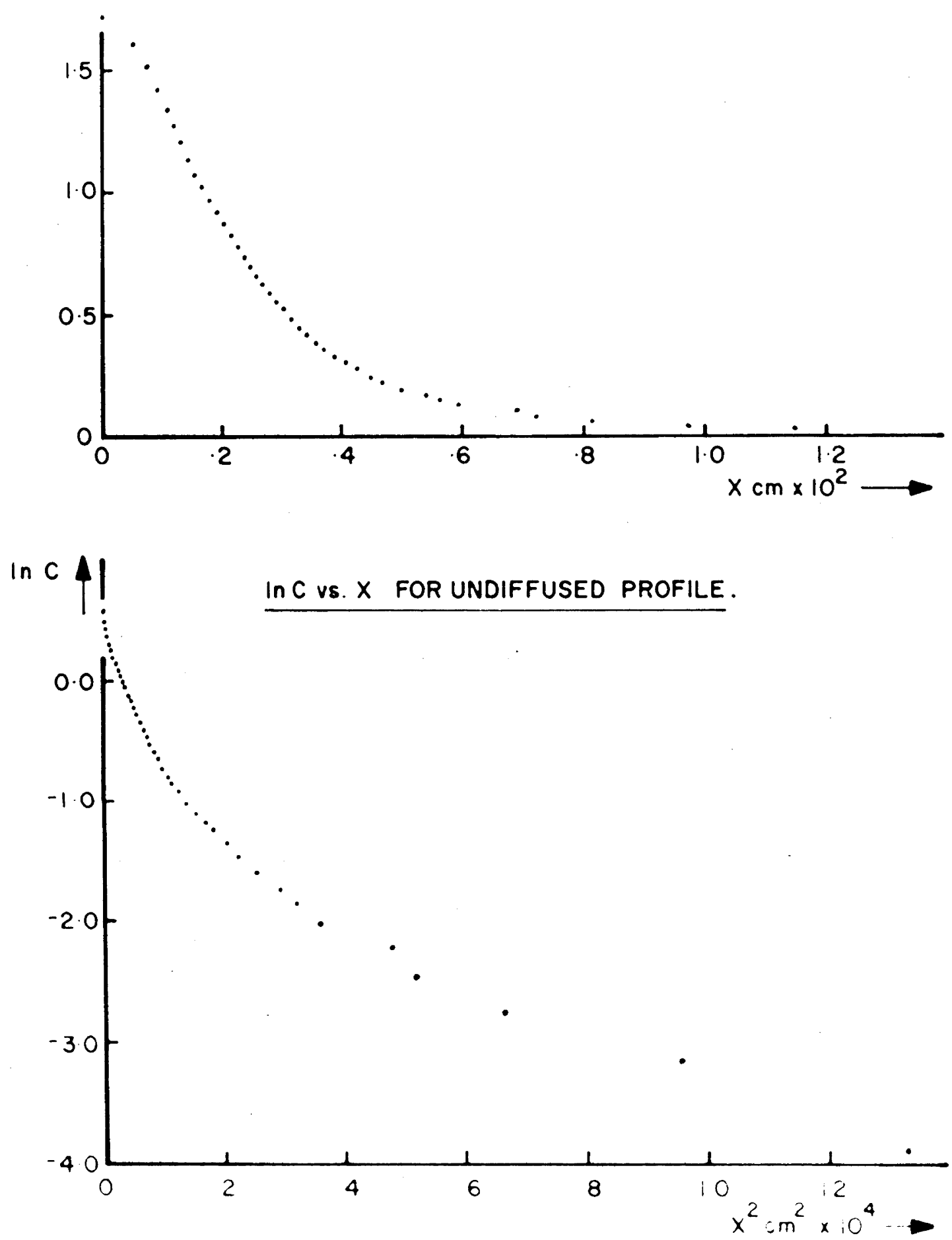

FIG 46 
because the measurement of the angle introduces a $10 \%$ uncertainty in the final diffugion coefficient. Therefore the accuracy that could be gained by better resolution is lost in the measurement of the angle if the resolution correction is smaller than 10\%.) The magnitude of the resolution correction, or (Dt) res, will be the same in the case of the angle-cutting as in the case of the longitiudinal sectioning. This is so because, the film sees the same kind of radioactivity distribution as in the case of the longtitudinal sectioning. Therefore the same resolution correction must apply. However, because the apparent $D t$ found by angle-cutting is increased by a factor of $1 / \sin ^{2} \theta$ the percentage resolution correction will be reduced by $\sin ^{2} \theta$. Liniarity

The photographic density of the exposure on the $\mathrm{X}$-ray film is defined as $\log \left(I_{0} / I\right)$ where $I_{0}$ is the amount of light transmitted through the unexposed part of the film and $I$ is the amount of light transmitted through the exposed part. It is found that the concentration of radioactivity is directly proportional to the photographic density up to a maximum value for $\log \left(I_{0} / I\right)$. This is called the linear range of the film. In this case it was determined by exposing the Hicrotex film with a ${ }^{14} \mathrm{C}$ source for various times. The ${ }^{14} \mathrm{C}$ was chosen because it was readily available in a convenient form and 
since it has the same type of radiation as ${ }^{45} \mathrm{Ca}$. The resultant graph is shown in figure 4.7 , from which it can be seen that the linear range of Microtex film for $\beta$-particle expogure extends up to a value for $\log _{10}\left(I_{0} / I\right)$ of at least 1.5 . In the present case a value of one for $\log _{10}\left(I_{0} / I\right)$ was not exceeded Shrinkage, Alignment and Smearing

As all photographic emulgions tend to shrink when developed, care must be taken that the dimensions measured on the film are corrected to dimensions on the crystal. In this case the film shrinkage was measured to be approximately $1 \%$ so that the diffusion coefficients have to be iricreased by $2 \%$. If the autoradiograph is not scanned exactly at right angles to the original interface, this will produce an apparent magnification of the diffusion zone, analogous to anglecutting. It is estimated that the interface can be lined up with the slit to within $1^{\circ}$ so that the value of $\theta$ to be applied in eqn. 4.1 is $89^{\circ}$. Thus the error introduced due to misalignment can only increase $D$ by $.04 \%$.

A third possible source of error during autoradiography is the production of a false image, due to smearing of the radioactivity or chemical reaction between the specimen and the film. During the present work no evidence of this effect was found but when there was any suspicion that smearing could have occured the specimen was again ground, washed and autoradiographed. 


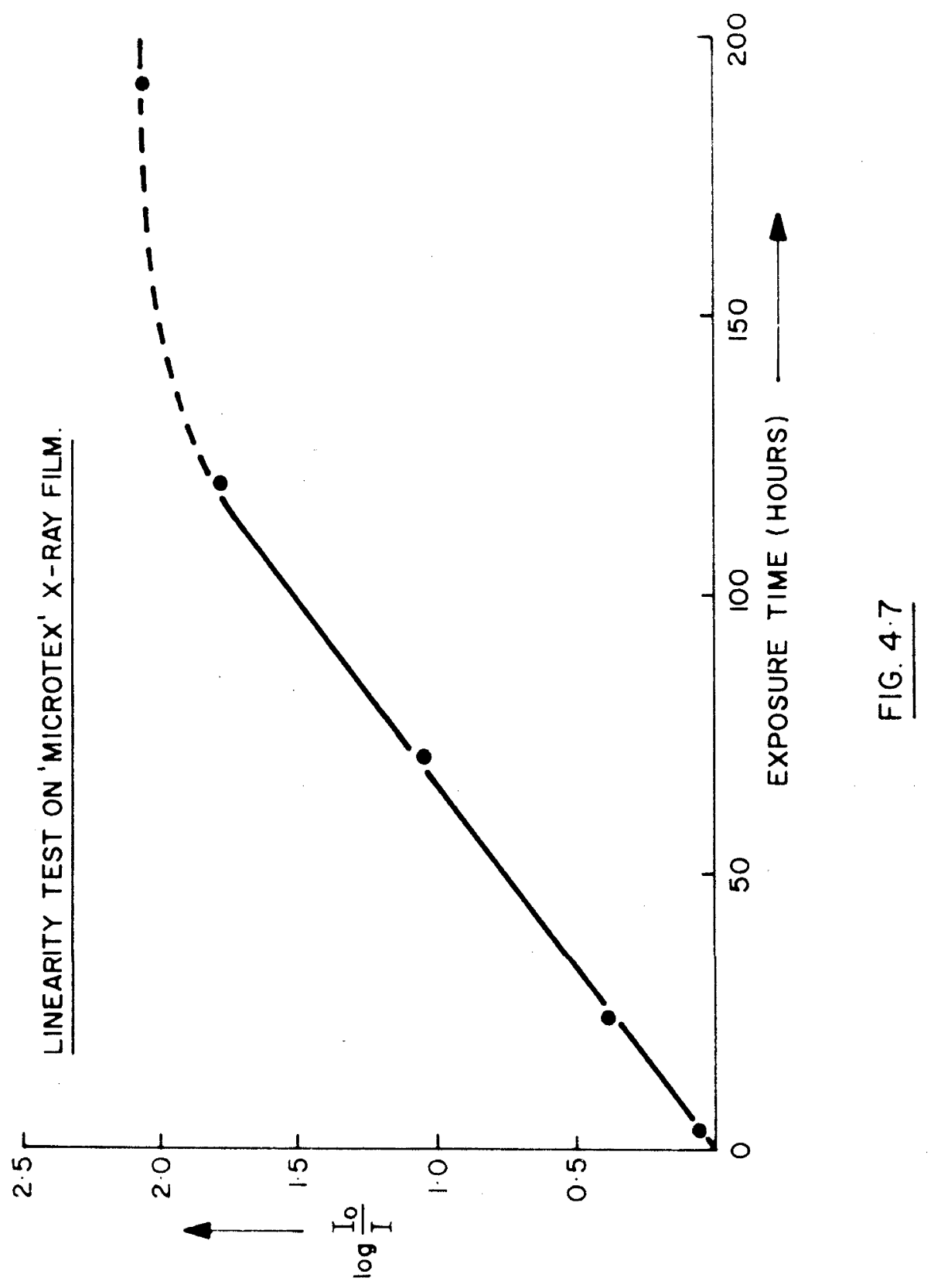


Analysis of Penetration Profiles

The $x, I$ data obtained from the charts were fed into an IBM 1620 computer which was programmed to evaluate the corresponding $x, C$ data (from $\ln \left(I_{0} / I\right)=C$ ) and then to fit straight lines of the form $C$ vs. $x^{2}$ and $\ln (d C . d x) v s \cdot x^{2}$ as discussed in chapter 3. Some typical curves obtained are given in figures $3.2,4.6$, and others can be seen in figures 4.8 and 4.9 .

Because the amount of calcium deposited could not be controlled as accurately as envisaged at the start some penetrations showed a Gaussian profile instead of the more usual error function type. That is, too small an amount of calcium appeared to have been deposited in these cases. Those diffusion coefficients which were calculated from a Gaussian profile or from a profile which was somewhere between Gaussian and error function, were excluded from subsequent calculations.

The largest errors auring the analysis occur because of the uncertainty in the choice of $I_{0}$, the unexposed level and $x_{0}$, the position of the original deposit. If the value of $I_{0}$ was increased or decreased by $1 \%$ the diffusion coefficient correspondingly increased or decreased by $10 \%$. Thus, because it was estimated that $I_{0}$ could be measured to only $\pm 1 \%$, this introduced an error of $\pm 10 \%$ in the diffusion coefficient. It was found that a change of $.01 \mathrm{~cm}$ in $x_{0}$ on the chart produced 

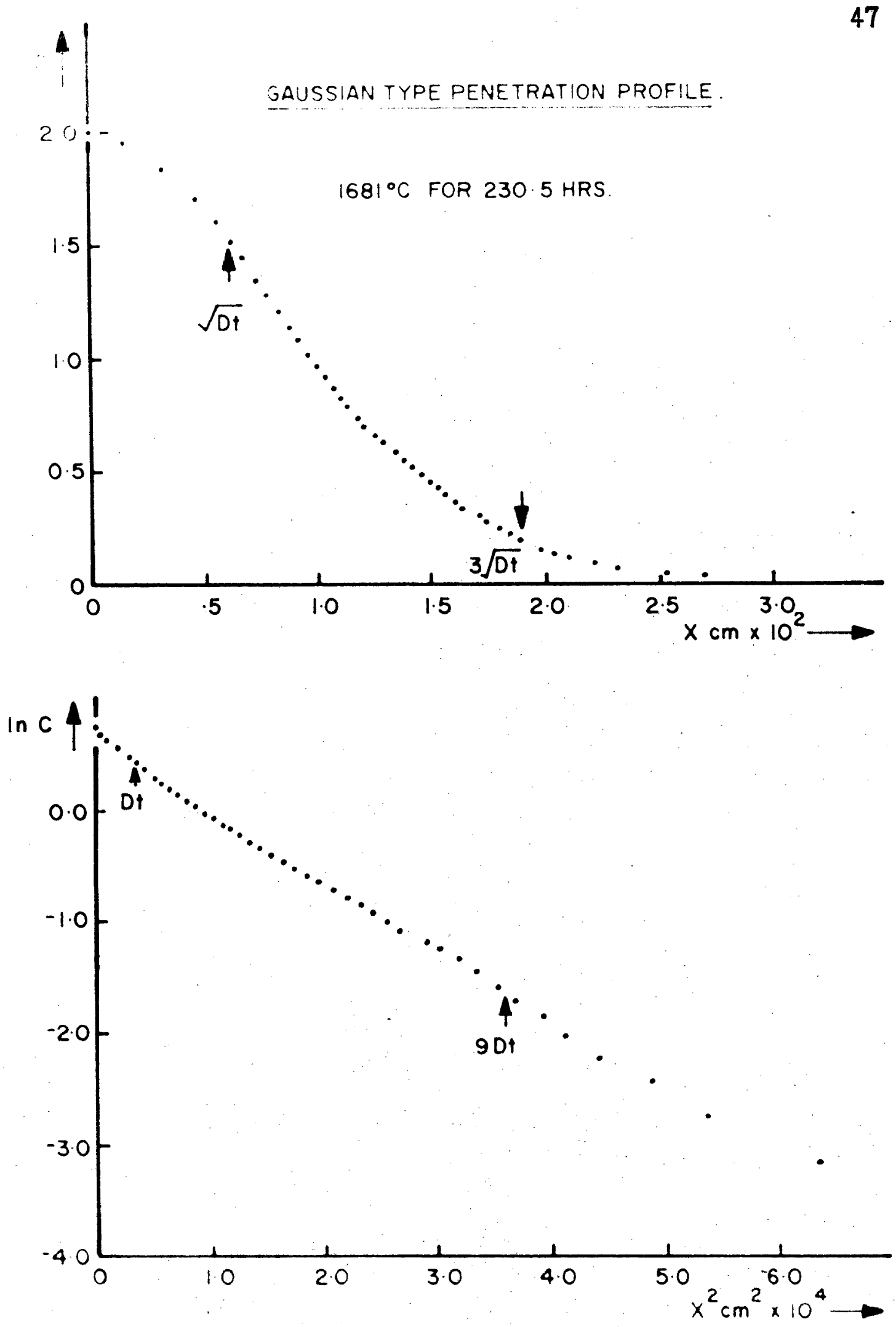

FIG. $4: 8$ 

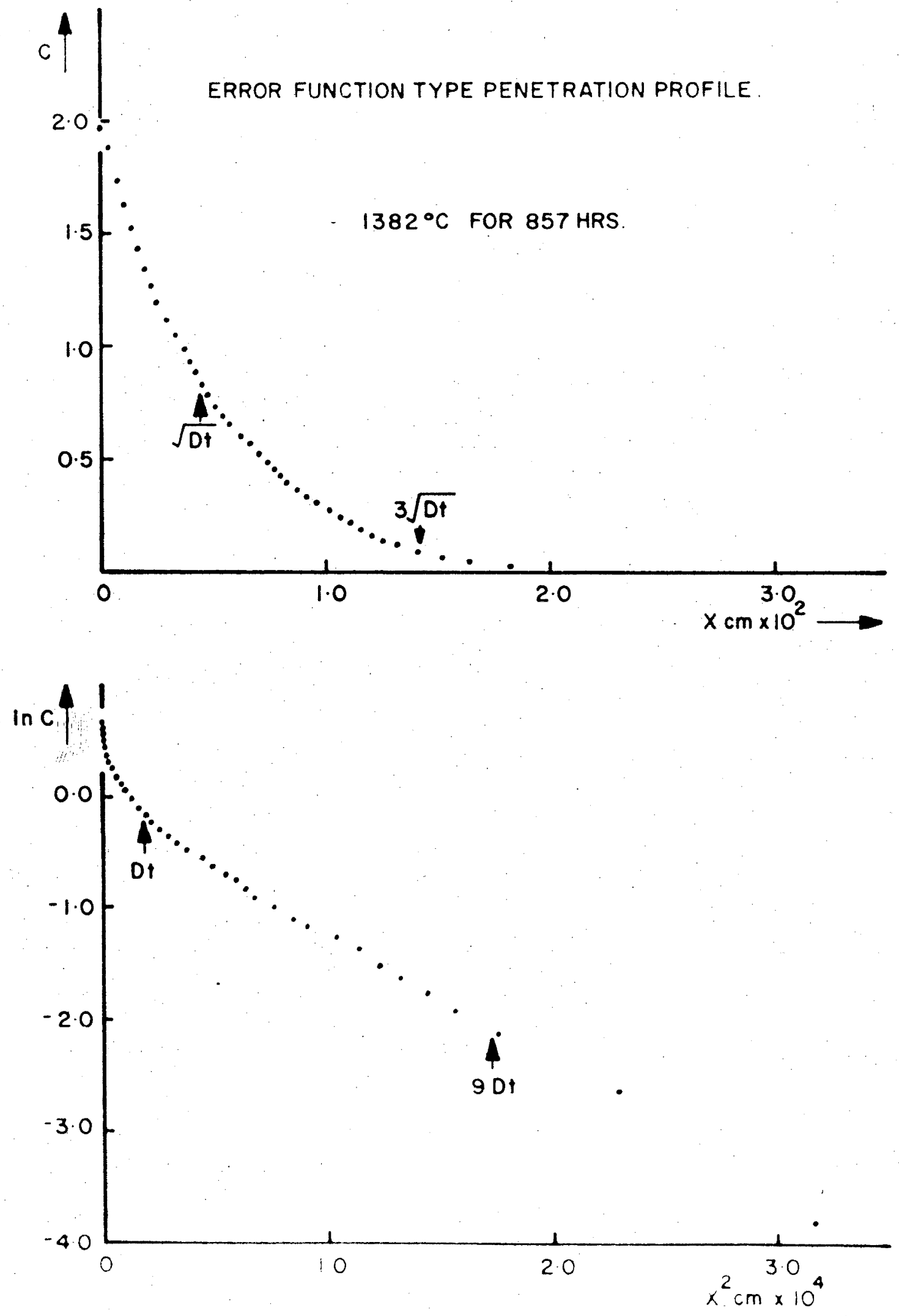
approximately an $0.5 \%$ change in $D$ but that an equal change on both sides of a symmetric scan (plus on one side, minus on the other) produced only an $0.03 \%$ change in the average D. In some scans an estimated error as high as $\pm 0.5 \mathrm{~cm}$ on the chart could occur in the choice of $x_{0}$ so that an error of $\pm 25 \%$ will result in the individual D's but the average across the scan will only have an uncertainty of $\pm 1.5 \%$. The above discussion has assumed that the two crystals forming the sandwich are in intimate contact and that there is no gap between them. From observations of the diffusion couples under a microscope it was difficult to determine whether any such gap existed, but if it did exist, it was no more than $.002 \mathrm{~cm}(.2 \mathrm{~cm}$ on chart). This would increase the diffusion coefficient on both sides of the scan by $5 \%$. As mentioned in the previous chapter, the diffusion coefficients have to be worked out between the same limits of Dt for $x$ in each case if the theory given in chapter 3 is to be applied. However it was found that this could not be achieved in all cases and an uncertainty of $8 \%$ in $D$ was estimated to be produced by the variation in the limits for $x$. The accuracy of the conversion factor used for changing from length on chart to length on crystal has already been mentioned. However, in the case of angle-cutting, another variable, the measurement of the angle, is introduced. The crystal was mounted on a $j i g$ and measured before and after 
cutting in the same geometry, by the travelling microscope as shown in figure 4.10. It was estimated that this angle could be measured to an accuracy of $\pm \frac{1}{4}^{\circ}$ at $5^{\circ}$. This means an error of $\pm 5 \%$ in the angle or $\pm 10 \%$ in the diffusion coefficient. Also, it was found that estimation of $x_{0}$ was more difficult in the case of the angle-cutting. Summary of Errors

Summary of the errors mentioned above is given in table 4.1. It can be seen that after correcting for systematic errors, individual diffusion coefficients at $1500^{\circ} \mathrm{C}$ can be quoted to an accuracy of $18 \%$ in the came of the longtitudinal section and $20 \%$ in the case of angle-cutting. At lower temperatures the errors will be higher - up to $30 \%$ at $1000^{\circ} \mathrm{C}$. 


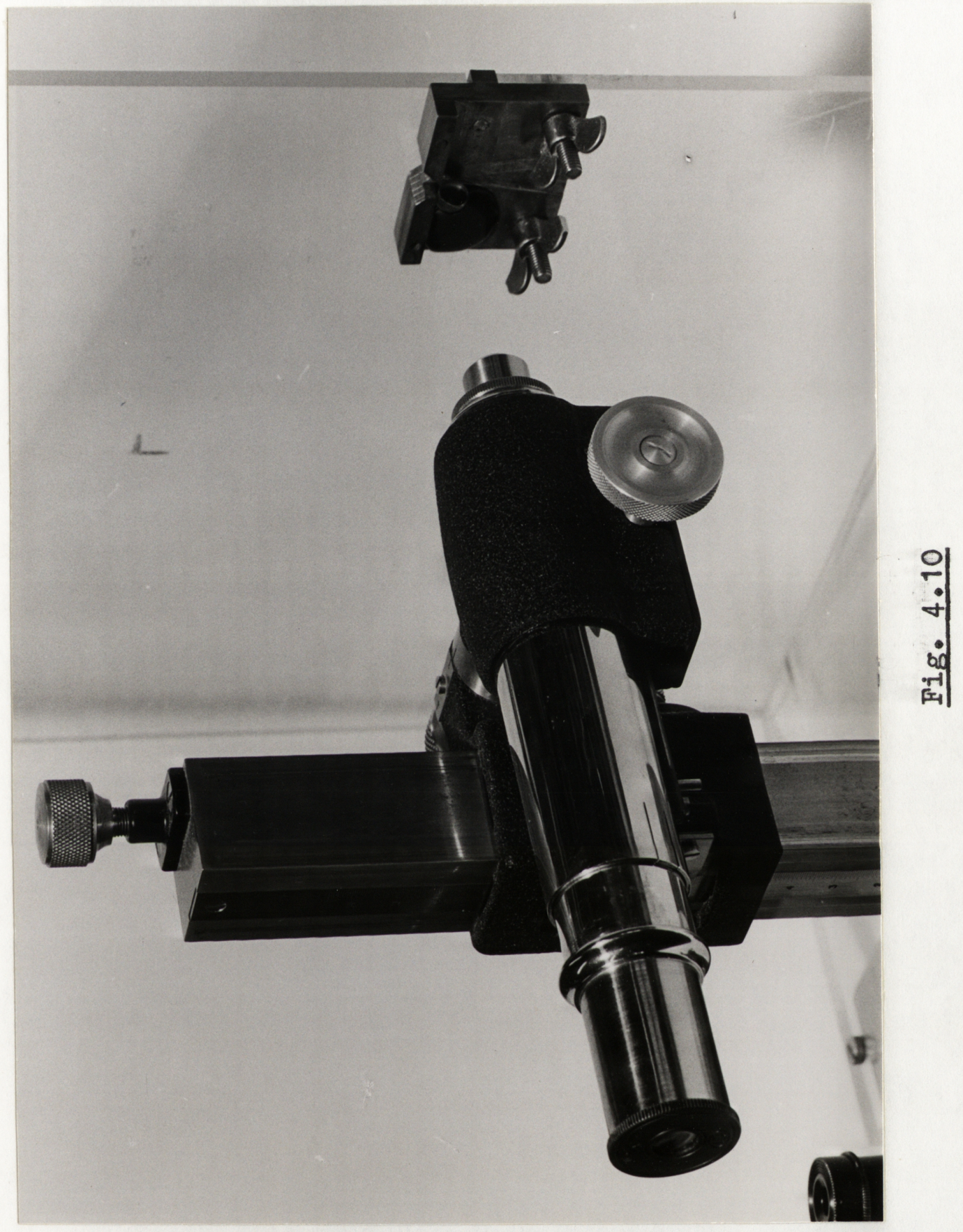




\section{Table 4.1}

Typical Magnitudes of Random Errors at $1500^{\circ} \mathrm{C}$

Variable

Temperature measurement

Time

Conversion factor (length on chart/length on film)

$x_{0}$

$I_{0}$

Iimits for $x$

\section{Error in Diffusion coefficient}

$$
\begin{aligned}
& \pm 10 \% \\
& \pm .04 \%
\end{aligned}
$$

$\pm .3 \%$

$\pm 10 \%$

$\pm 10 \%$

$\pm 8 \%$

Total* $\quad \pm 18 \%$

In addition to these, in the case of angle-cutting: Angle measurement

$\pm 10 \%$

Total* $\quad \pm 20 \%$

*This total is the square root of the sum of the squarea of the individual errors. 
REFERENCES Chap. 4

(1) A. F. Brown \& D. A. Blackburn, Acta Met., 11, 1017 (1963) 


\section{PRINCIPAI RESULTS}

Ca in Single Crystal MgO

The diffusion coefficients found by the techniques given in the previous chapters for $\mathrm{Ca}$ diffusing into single crystal MgO are listed in table 5.1 and plotted as a graph of $\log _{10} \mathrm{D}$ vs. $1 / T$ where $T$ is the absolute temperature in figure 5.1. In all cases the diffusion coefficients were calculated by fitting an equation of the Gaussian type to the observed penetration profiles and each plotted point is the mean of all the coefficients calculated from a single autoradiograph. A straight line of the form $\log D=\log D_{0}-Q / \mathrm{kT}$ was fitted by least squares to the points which were derived from an error function profile. In this way $Q$ was calculated to be $2.1 \pm 0.2 \mathrm{eV}$ and $D_{0}=\left(1.8_{-0.9}^{+1.6}\right) \times 10^{-5} \mathrm{~cm}^{2} / \mathrm{sec}$.

The variation of the diffusion coefficients found from scans of the one autoradiograph are shown in table 5.2 and figure 5.2. The data in table 5.2 is set out in positions corresponding to the positions on the autoradiograph from which the diffusion coefficients were calculated. The "error bars" in figure 5.2 represent by their limits the maximum and minimum values found in each run; for clarity, the points at $910^{\circ} \mathrm{C}$ and $1051^{\circ} \mathrm{C}$ have been omitted to allow the scale to be expanded. 


\section{Table 5.1}

The Diffusion Coefficients

$$
\text { of }
$$

Calcium in Single Crystal Magnesium Oxide

Cemperature

$\left({ }^{\circ} \mathrm{C}\right)$

910

1051

1270

1382

1454

1458

1464

1537

1544

1545

1571

1604

1617

1671

1676

1681

1700
Time

(hr)

$3,168.0$

$2,184.0$

754.0

857.0

672.0

738.0

978.0

691.5

426.0

341.6

347.7

192.0

157.5

235.5

169.0

230.5

35.8
Diffusion

Coefficient

$\left(\mathrm{cm}^{2} / \mathrm{sec}\right)$

$2.06 \times 10^{14}$

8.76

$2.32 \times 10^{-12}$

7.92

9.97

8.22

9.35

$1.20 \times 10^{-11}$

3.43

3.11

1.83

4.41

3.83

6.71

7.88

4.23

6.54
Profile

Type

E

E

E

E

G

E

G

E

E

G

E

E

E

G

E

G

E

*E and $G$ indicate error function or Gaussian profile respectively. 


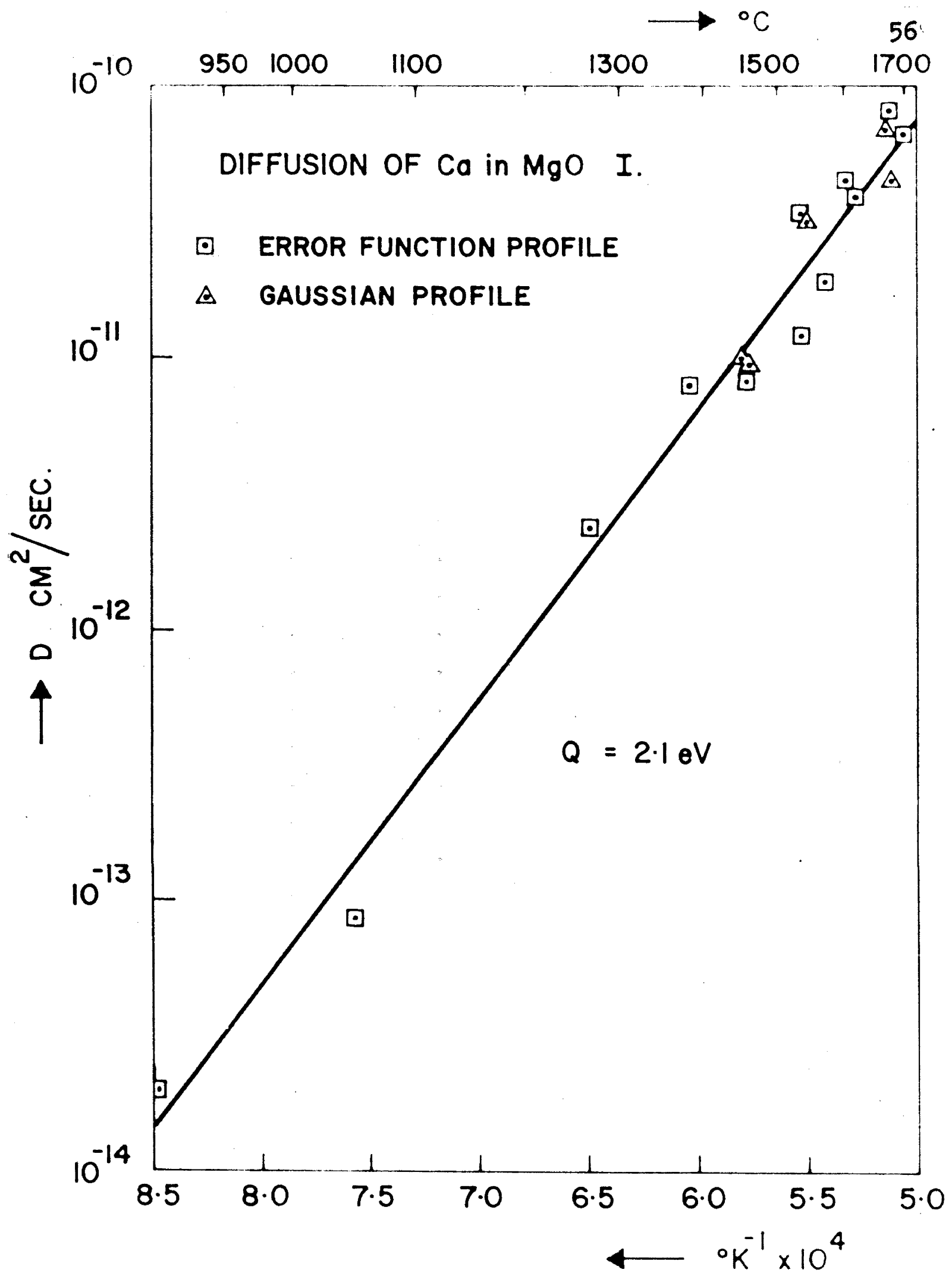

FIG. $5 \cdot 1$ 


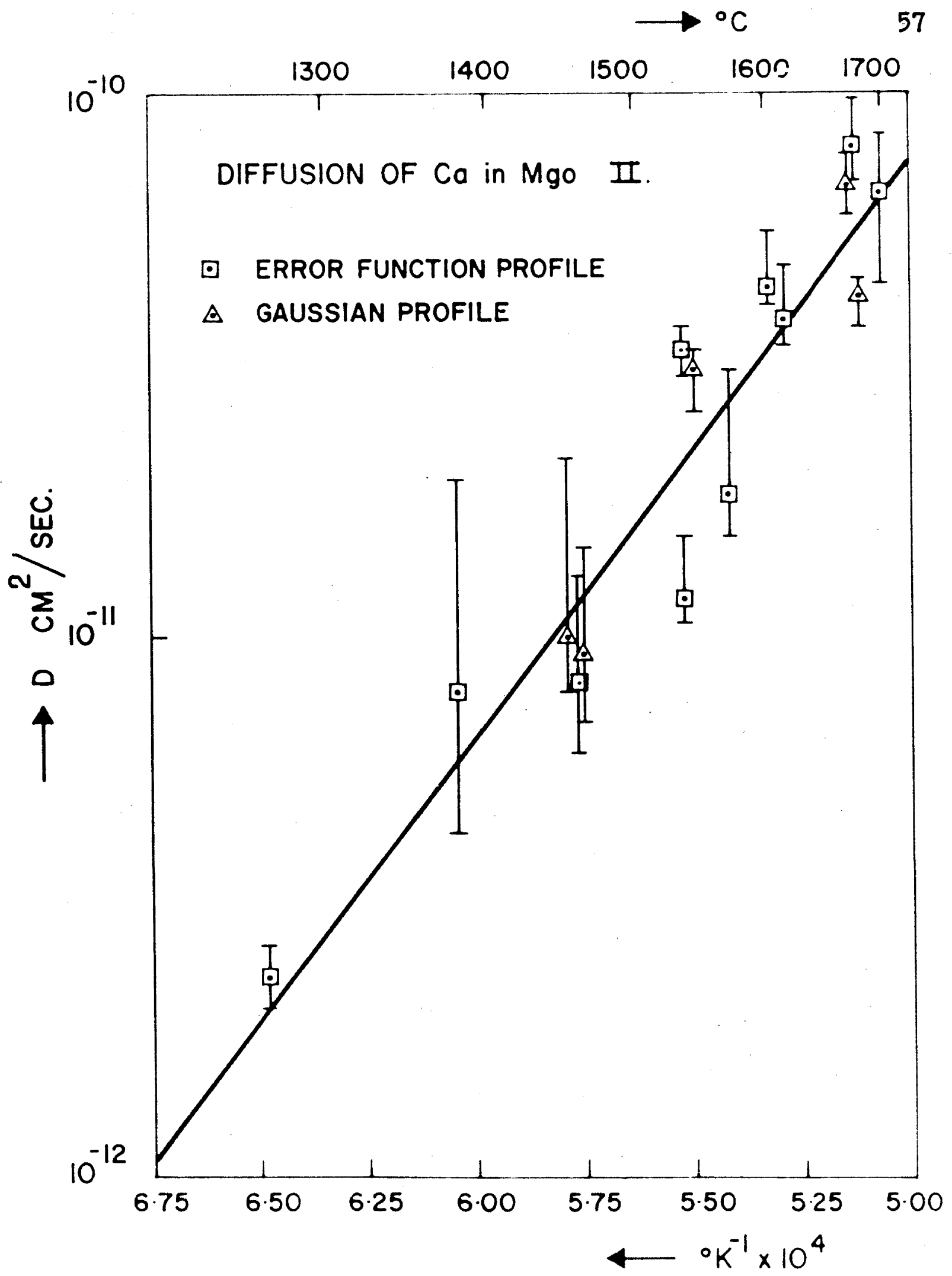

FIG. $5 \cdot 2$ 


\section{Table 5.2}

\section{Variation of D Within a Single Specimen}

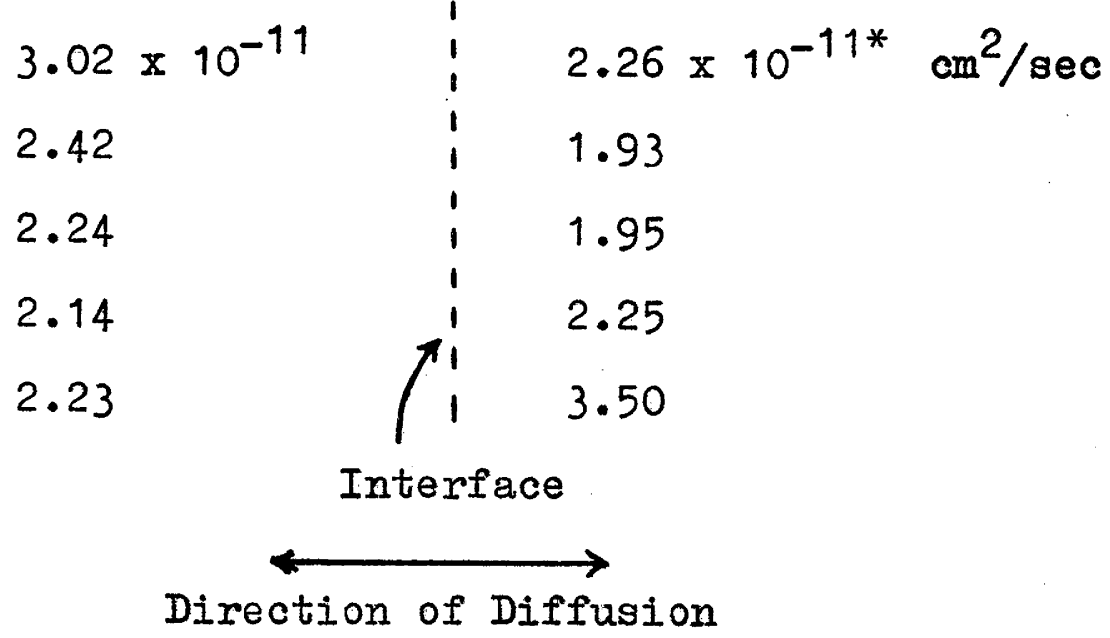

Temperature: $1571^{\circ} \mathrm{C}$

Time: $\quad 347.7 \mathrm{hr}$.

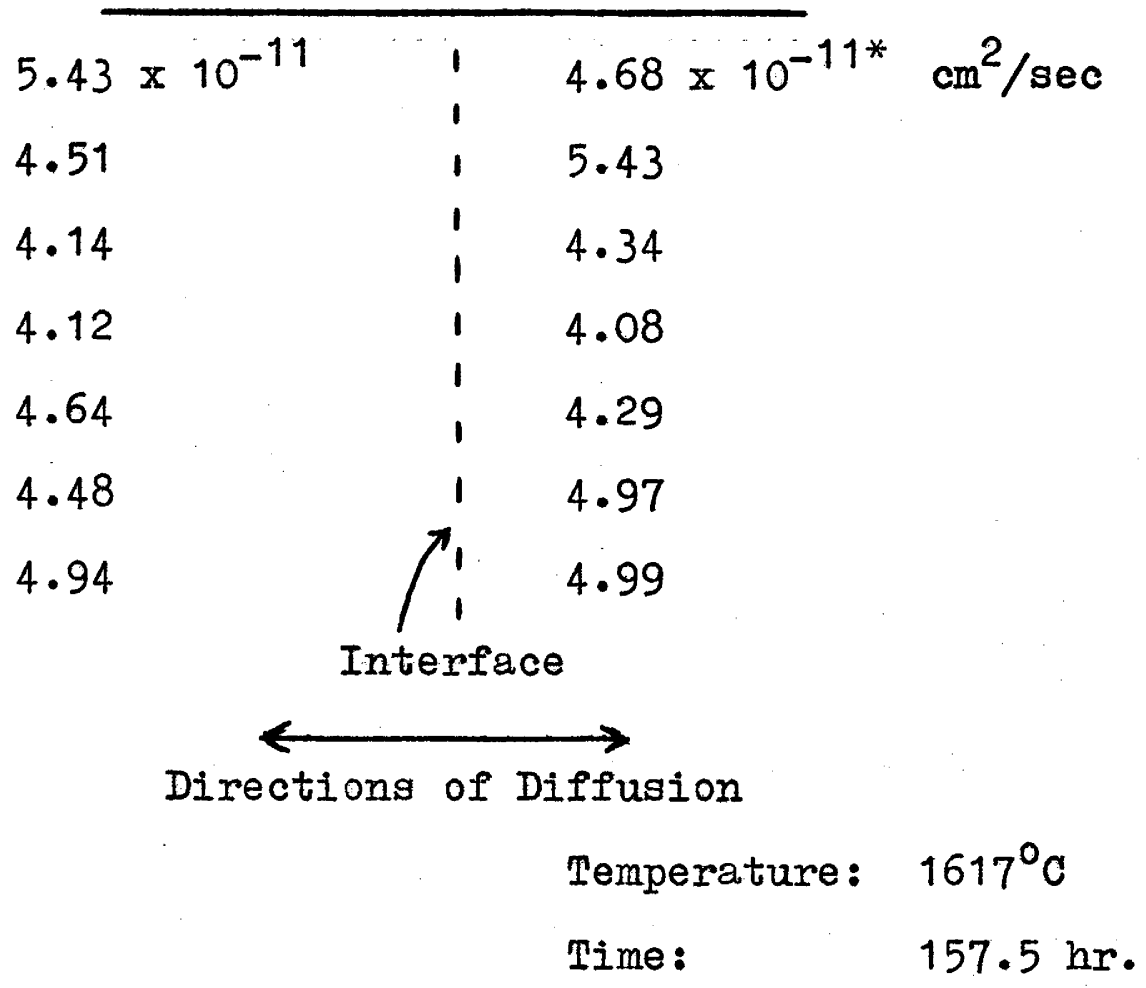

*The microphotometer slit width for each scan was $0.05 \mathrm{~cm}$ and the average distance between centre lines of each scanning path was $0.08 \mathrm{~cm}$. 
Table 5.3 shows the comparison of $D^{\prime}$ s calculated by the Gaussian method and the error function method. The average standard deviation for the least squares fit to the line $\ln (d \epsilon / d x)$ vs. $x^{2}$ was $15 \%$ in the scans used whereas the average standard deviation for the least squares fit to the line lne vs. $x^{2}$ was only $2 \%$.

Ni in Single Crystal MgO

Three experiments of the same type as described above for Ca were carried out for $\mathrm{Ni}$ diffusing into single crystal MgO. The tracer employed was $63 \mathrm{Ni}$ which was deposited as $\mathrm{NiCl}_{2}$ on the end faces of the crystals. All the observed penetration profiles were of the Gaussian type. The corresponding diffusion coefficients are ligted in table 5.4 and plotted graphically in figure 5.3 .

Ca in Polyorystalline Mg0

Two diffusion rung were carried out using the two types of polycrystal purchased. In both cases the radioactive calcium chloride solution was deposited on a single crystal and when this had dried, a polycrystal was butted against it. The 0.1 mm grain size $(2,61 \mathrm{gm} / \mathrm{cc}$ density) was heated for eight weeks at $1286^{\circ} \mathrm{C}$. The penetration into the polycrystal was very much greater than into the single crystal as shown in figure 5.4 which is a $10 \mathrm{X}$ enlarged photograph of the resultant autoradiograph. A comparison with lattice diffusion is possible if the penetration is assumed to be proportional to $\sqrt{D t}$. At 


\section{Table 5.3}

Comparison of diffusion coefficients calculated by the Gaussian method and the error function method from data having an error function profile.

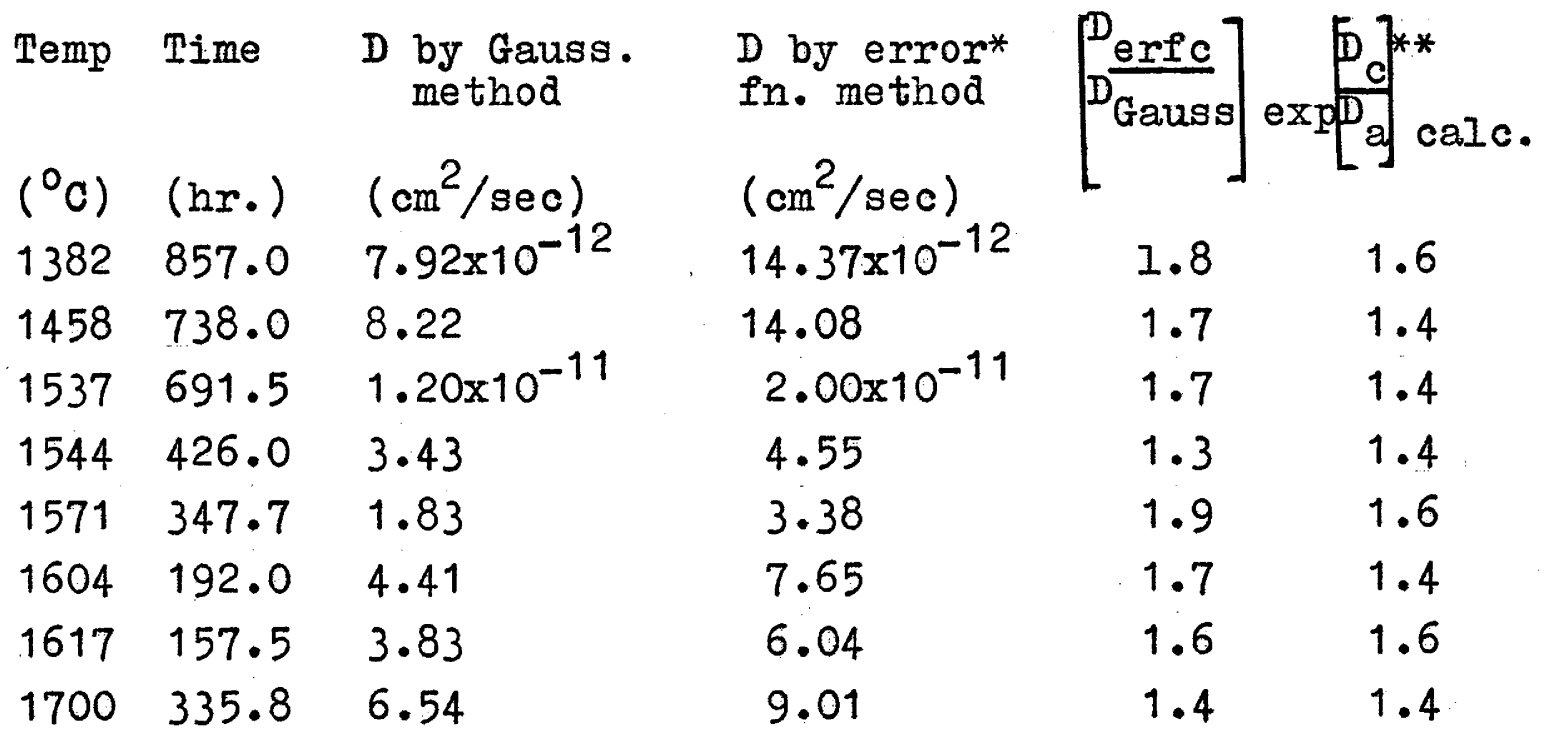

*These diffusion coefficients were calculated from the slope of the straight line $\ln (\mathrm{dc} / \mathrm{dx})$ va. $\mathrm{x}^{2}$ as discussed in chapter 3. Because of the scatter of the experimental points this analysis could only be applied in a few cases and therefore these $D^{\prime}$ s are the average of only 2 to 3 scans out of a total number of 8 to 10 from the one autoradiograph.

**These averages were calculated by numerically integrating the curve $D_{c} / D_{a}$ vs. $x / D_{c} t$ between the limits of $\sqrt{D_{c} t}$ operating for $x$. There is a variation in these values because the limits of $\sqrt{D_{c} t}$ operating for $x$ varied slightly between the different runs. 


\section{Table 5.4}

Diffusion Coefficients

of

Nickel in Single Crystal Magnesium Oxide

Temperature

$\left({ }^{0} \mathrm{C}\right)$

1458

1544

1604
Time

(hr)

738.0

426.0

192.0
Diffusion Coefficient

$\left(\mathrm{cm}^{2} / \mathrm{sec}\right)$

$1.59 \times 10^{-11}$

$6.23 \times 10^{-11}$

1. $97 \times 10^{-10}$ 


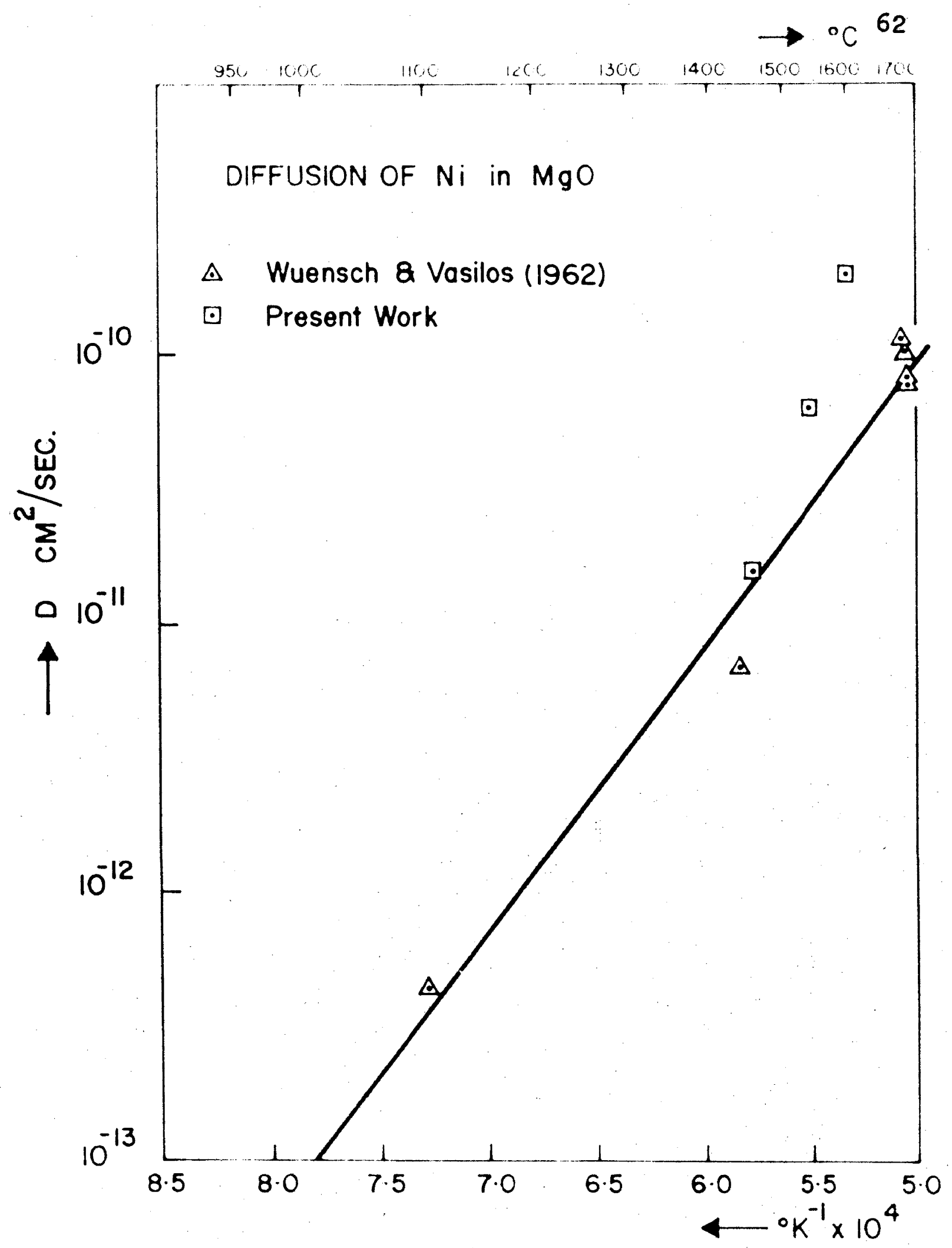

FIG. $5 \cdot 3$ 
Interface

$\div \downarrow$

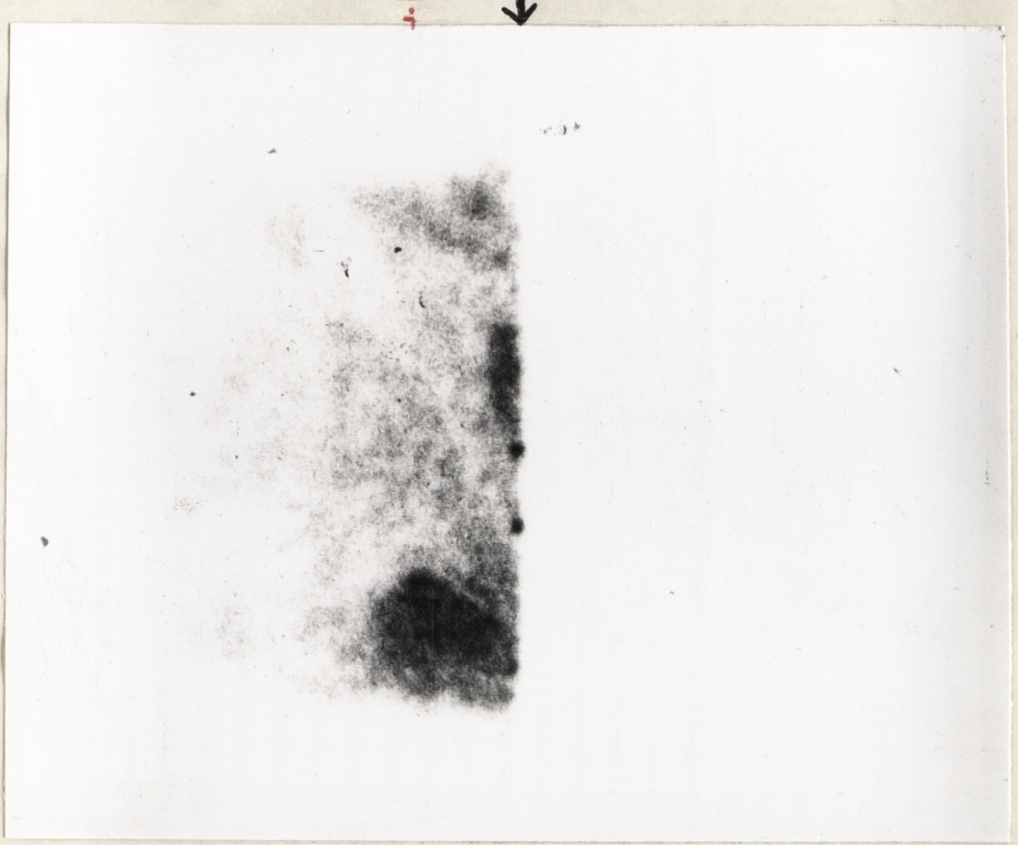

Polycrystal Single Crystal

Autoradiograph of Diffusion Zone in

Polycrystalline MgO specimen

after heating at $1286^{\circ} \mathrm{C}$ for 8 weeks

Magnification $\mathrm{X} 10$

Fig. 5.4 
$1286^{\circ} \mathrm{C}$ it is found in this way that the apparent diffusion coefficient operating in the polycrystal is about $10^{4}$ times greater than the corresponding lattice diffusion coefficient.

The other polycrystalline couple was made from $1 \mathrm{~mm}$ grain size material and was heated at $1051^{\circ} \mathrm{C}$ for three months. Figure 5.5 shows a photograph of the actual crystal and the associated autoradiograph, both having a magnification of 10 . It can be clearly seen that the penetration along the grain boundaries is much larger than into the grains or into the single crystal. As above, taking the penetration as proportional to $\sqrt{\mathrm{Dt}}$ it is found that at $1051^{\circ} \mathrm{C}$ the apparent diffusion coefficient operating in the polycrystal is again about 10.4 times greater than the corresponding lattice diffusion coefficient. 


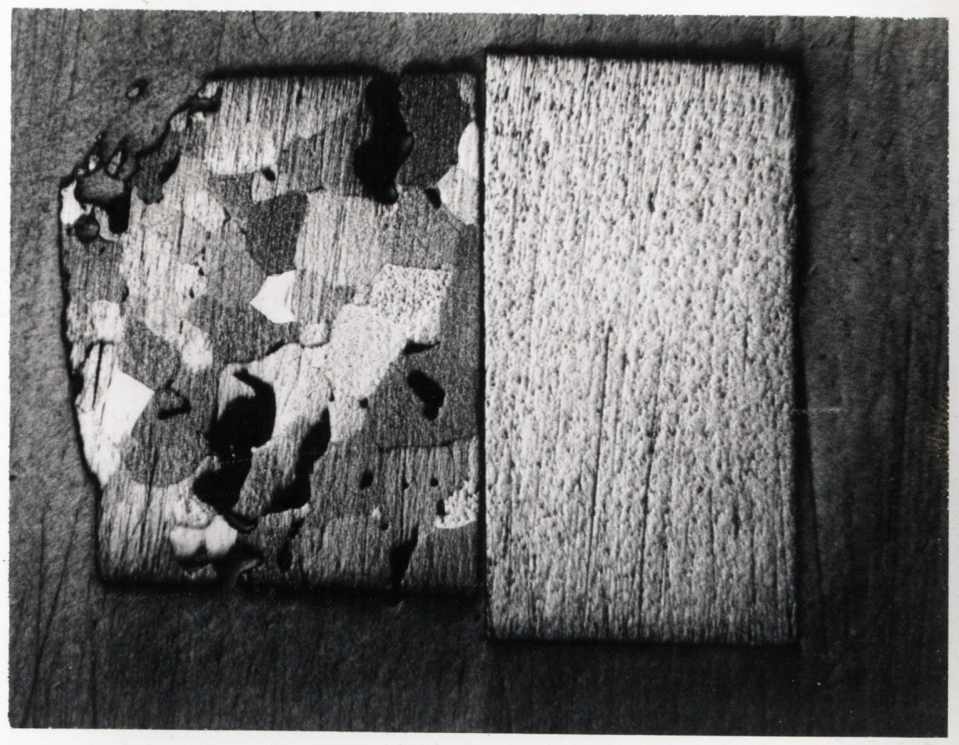

Polycrystalline and Single Cryatal ligo Diffusion Couple

Hagnification X10

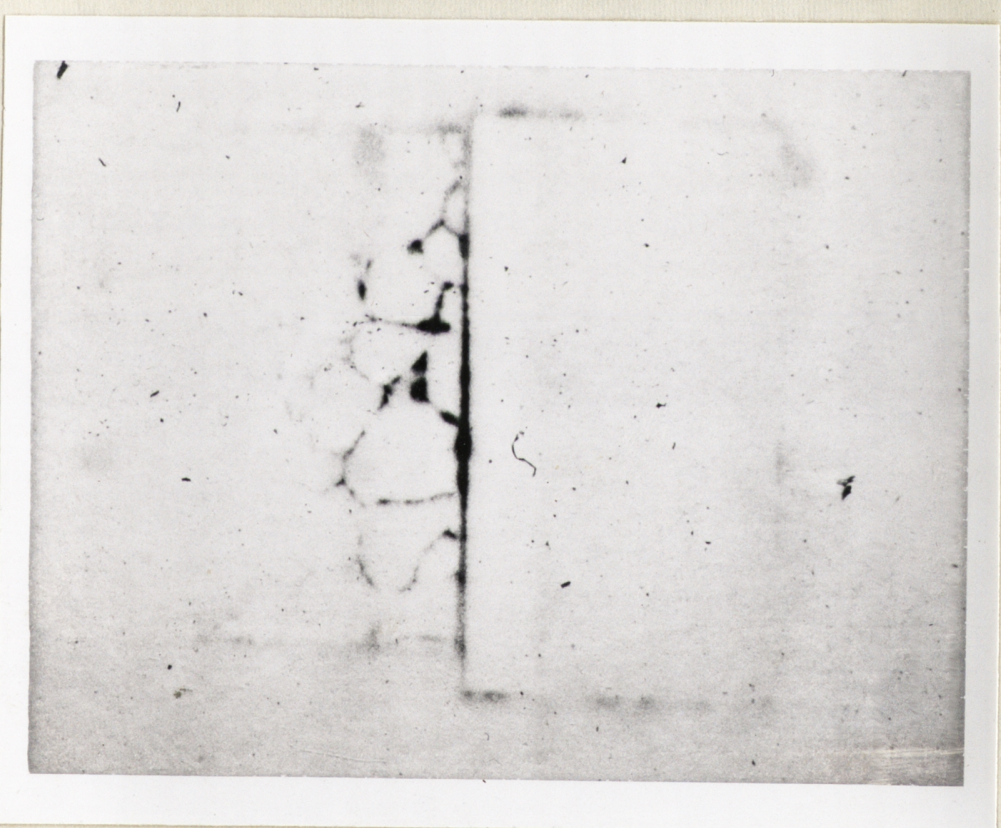

Autoradiograph of the above Diffualon Couple after heating at $1051^{\circ} \mathrm{C}$ for 13 weeks Magnification X10 


\section{DISCUSSION}

Agreement with Published Data.

It was noted in chapter one that the activation energies obtained by Wuensch and Vasilos for diffusion of the transition metal ions in single crystal magnesium oxide and the activation energy for the self-diffusion of magnesium oxide could be related by the equation:

$$
\left.\log _{10}\left(Q / k_{1}\right)=k_{2}(r / \alpha) \ldots \ldots \ldots \ldots \ldots \ldots \ldots \ldots .16 .1\right)
$$

Taking the ionic radius ${ }^{1}, \mathrm{r}$, for $\mathrm{Ca}^{++}$to be $1.0 \times 10^{-8} \mathrm{~cm}$ and the ionic electronic polarizability ${ }^{2}, \alpha$, to be $0.5 \times 10^{-24} \mathrm{~cm}^{3}$ substitution in this equation predicts that the activation energy for the diffusion of calcium in magnesium oxide should be $1.9 \mathrm{eV}$. It is clear that the present value of $2.1 \pm .2 \mathrm{eV}$ is consistant with this correlation. If the data for $\mathrm{Ca}$ is included in the evaluation of the constants in eqn. 6.1, more general values for $k_{1}$ and $k_{2}$ become available:

$$
\begin{aligned}
& k_{1}=1.47 \mathrm{eV} \\
& k_{2}=0.0623 \times 10^{-16} \mathrm{~cm}^{2}
\end{aligned}
$$

The fact that the correlation originally established for the transition metal ions has now been found to hold for calcium means that it may be possible to extend it to the diffusion of all bivalent metal ions in magnesium oxide. Further, it suggests that the same mechanism of diffusion operates in all these caseg. 
Mechanism of Diffusion

More information is required to determine the mechanism of diffusion, as a simple determination of the activation energy is not usually sufficient. One such property which is closely related to thermal diffusion is the electrical conductivity of the material. In a solid like magnesium oxide two distinct modes of electrical conductivity are possible. Firstly, the transfer of electricity can take place by the motion of cation and anion vacancies, or by the motion of the lons as interstitials through the lattice. This is called ionic conductivity. Secondly, conduction can take place by the motion of electrons due to excess magnesium or the motion of positive holes due to excess oxygen or the motion of intringic electrons and holes if the magnesium oxide behaves as a semiconductor at elevated temperatures This is referred to as electronic conductivity

Experimentally, the important difference between these two modes is that if the conductivity is electronic there is no nett mass transfer under the influence of an electric field while if it is ionic there is a nett mass trangfer. A consequence of this is that if $\mathrm{MgO}$ is an electronic conductor, defects which participate in the observed diffusion must be neutral.

Mitoff ${ }^{3}$ reports that the conductivity of $\mathrm{MgO}$ at $1300^{\circ} \mathrm{C}$ is electronic rether than ionic, therefore cation diffusion must take place by one of the following mechanisms: 
(a) cation exchange with mobile neutral cation vacancycation impurity pairs.

(b) cation exchange with mobile neutral cation-anion vacancy pairs.

(c) direct exchange of cations in pairs or by a ring-offour mechanism.

Each one of these mechanisms will have a certain probability but further experiments would have to be carried out to see which is the predominant one. In mechanism (a) the impurity referred to is not the diffusing or tracer impurity whose motion is being studied, but it is an impurity already present in the crystal before the diffusion annealing takes place. If this mechanism is the predominant one the addition of multivalent impurities to the MgO should strongly increase the diffusion rate. The excess positive charge of the added impurities would attract cation vacancies and the tendency to form stable, mobile cation vacancy-cation impurity pairs would be greatly increased and therefore if the diffusion rate depended on the formation of this type of defect, it would also be increased.

If doping with multivalent impurities does not increase the diffusion rate then mechanism (b) or (c) operates. Of the two possible modes in mechanism (c) the direct exchange must be given little weight because it has been found ${ }^{4}$ that in metals the energy required for such a movement is prohibitively 
large and the same is probably true of $\mathrm{MgO}$. To determine whethe: cations diffuse by exchange with cation-anion vacancy pairs or by a ring-of-four mechaniam an isotope experiment of the type carried out ${ }^{5}$ for iron diffusing into copper may have to be carried out.

The fact that no change in the activation energy for difussion was found in the range $1000^{\circ} \mathrm{C}$ to $1700^{\circ} \mathrm{C}$ means that the type of conductivity found at $1300^{\circ} \mathrm{C}$ by Mitoff probably extends up to $1700^{\circ} \mathrm{C}$. Wuensch and Vasilos ${ }^{6}$ suggest that the existence of stable cation-anion vacancy pairs at these temperatures would require an association energy which is rather high. For this reason they favour a simple cation-cation vacancy exchange mechanism despite Mitoff's finding of no ionic conductivity. This view is supported by Schmalzried ${ }^{7}$ who disagrees with Mitoff and finds that conduction in MgO is ionic. The problem cannot be resolved one way or the other as the conductivity experiments were carried out on relatively impure Mgo (iron being the predominant impurity). When conductivity measurements are made on the purer crystals now available the picture might be clarified.

Homogeneity of Crystals

As shown in table 5.2 and figure 5.2 the variation of the individual diffusion coefficients within a specimen was found in the majority of runs to be no larger than expected from the error limits operating in these experiments. However, although 
all runs were carried out under identical experimental conditions, some specimens showed an unusually large fluctuation in the diffusion coefficient. This occasional large variation was not found preferentially in any particular region of the crystals used, and so can be attributed to random inhomogeneity. This is probably due to an uneven distribution of impurities or dislocations both of which can strongly influence rates of diffusion.

\section{Frequency Factor}

The value of $1.8 \times 10^{-5} \mathrm{~cm}^{2} /$ sec. obtained for the frequency factor, $D_{0}$, is the same order of magnitude as the value obtained for the diffusion of the transition metal ions in $\mathrm{MgO}$. As table 5.3 shows, the discrepency between the experimental and theoretical values of $D_{c} / D_{a}$ is no greater than expected due to the probable errors in the individual diffusion coefficients. Therefore, applying the theoretical value for $D_{c} / D_{a}$ of 1.5 , the best value for $D_{0}$ that can be quoted is $2.7 \times 10^{-5} \mathrm{~cm}^{2} / \mathrm{sec}$. Ni in Single Crystal MgO

The results for niekel diffusing into single crystal magnesium oxide agree only at the lower temperatures with those quoted by Wuensch and Vasilos. At higher temperatures the present Ni results are higher than those quoted earlier. This result is contrary to the general finding that diffusion rates increase with impurity content, as the present crystals are purer than the ones used in the previous work. There does not seem to be any satisfactory explanation of this discrepancy available at this stage 
Ca in Polycrystalline MgO.

The large tracer penetrations observed in the case of calcium diffusing through polycrystalline MgO support the findings of Wuensch and Vasilos ${ }^{8}$ who found that the diffusion of $\mathrm{Ni}$ in polycrystalline $\mathrm{MgO}$ was controlled by grain boundaries at temperatures below $1700^{\circ} \mathrm{C}$ and is contrary to Zaplatynsky ${ }^{9}$ and others ${ }^{10}$ who found that the ratio of grain boundary diffugion to lattice diffusion in MgO was unity. However, because of the low densities ( $73 \%$ and $86 \%$ of single crystal density) involved, more experiments have to be performed to test whether the large penetrations observed are really due to diffusion or whether the calcium has penetrated by some other mechanism such as vapour transport. 


\section{REFERENCES Chap. 6.}

(1) I. Pauling, "The Nature of the Chemical Bond" Cornell University Press, 2nd. ed. (1945)

(2) N. F. Mott \& R. W. Gurney, "Electronic Processes in Ionic Crystals", p 14, O.U.P. (1940).

(3) S. P. Mitoff, J. of Chem. Phys., 31, 1261 (1959).

(4) H. B. Huntington \& F. Seitz, Phys. Rev., 61, 315 (1942) 76, 1728 (1949)

(5) I. W. Barr \& A. D. LeClaire, Proc. of the British Ceram. Soc., p 109, No. 1, Juzy 1964.

(6) B. Wuensch \& T. Vasilos, "Reactivity of Solids", Proceedings of the Fourth International Symposium on Reactivity of Solids, Amsterdam 1960. p 57, Elsevier Publishing Co., (1961).

(7) H. Schmalzried, J. of Chem. Phys., 33, 940 (1960).

(8) B. J. Wuensch \& T. Vasilos, J. of Am. Ceram. Soc. 47, 63 (1964)

(9) I. Zaplatynsky, J. Appl. Phys., 35, 1358 (1964)

(10) R. Shelly, E. B. Rigby \& I. B. Cutler, J. of Am. Ceram. Soc., 45, 302 (1962) 


\section{CONCLUSIONS}

The temperature dependence over the range $1000^{\circ} \mathrm{C}$ to $1700^{\circ} \mathrm{C}$ of the diffusion coefficient for $\mathrm{Ca}^{++}$diffusing into single crystal magnesium oxide can be expressed by the following equation:

$$
D=D_{0} \exp (-Q / k T)
$$

where $D_{0}=$ Irequency factor $=2.7 \times 10^{-5} \mathrm{~cm}^{2} / \mathrm{sec}$

$$
\begin{aligned}
& Q=\text { activation energy }=2.1 \mathrm{eV} \\
& \mathrm{k}=\text { Bolzmann's constant } \\
& \mathrm{T}=\text { absolute temperature }
\end{aligned}
$$

This result agrees with the correlation originally found by Wuensch and Vagilos for the diffusion of certain transition metal ions in single crystal magnesium oxfde. They found that the logarithm of the activation energy was proportional to the ratio of the ionic radiug of the diffusing cation to its ionic electronic polarizability. Combining all the results this can now be written:

$$
\log _{10}\left(Q / k_{1}\right)=k_{2}(r / \alpha)
$$

where $k_{1}=1.47 \mathrm{eV}$

$$
k_{2}=0.0623 \times 10^{-16} \mathrm{~cm}^{2}
$$

It is possibie therefore that this equation, with perhaps a slight change in the constants, will be found to apply for the diffusion of all bivalent metal ions in single 
crystal magnesium oxide. The mechanism of diffusion in all these cases has not yet been established but some further experiments may throw light on this problem.

It was also found that the apparent diffusion of calcium through low-density polycrystalline magnesium oxide took place predominantly along grain boundarieg. 